\title{
Laboratory observation and astronomical search of 1-cyano propargyl radical, $\mathrm{HCCCHCN}^{\star, \star \star}$
}

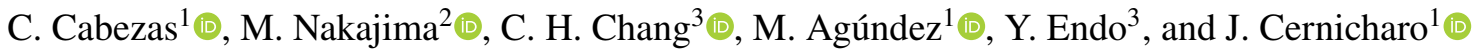 \\ ${ }^{1}$ Grupo de Astrofísica Molecular, Instituto de Física Fundamental (IFF-CSIC), C/ Serrano 121, 28006 Madrid, Spain \\ e-mail: carlos.cabezas@csic.es \\ ${ }^{2}$ Department of Basic Science, Graduate School of Arts \& Sciences, The University of Tokyo, Komaba 3-8-1, Meguro-ku, Tokyo \\ 153-8902, Japan \\ ${ }^{3}$ Department of Applied Chemistry, Science Building II, National Yang Ming Chiao Tung University, 1001 Ta-Hsueh Rd., \\ Hsinchu 300098, Taiwan
}

Received 9 September 2021 / Accepted 17 October 2021

\begin{abstract}
Context. The reaction between carbon atoms and vinyl cyanide, $\mathrm{CH}_{2} \mathrm{CHCN}$, is a formation route to interstellar 3-cyano propargyl radical, $\mathrm{CH}_{2} \mathrm{C}_{3} \mathrm{~N}$, a species that has recently been discovered in space. The 1-cyano propargyl radical $\left(\mathrm{HC}_{3} \mathrm{HCN}\right)$, an isomer of $\mathrm{CH}_{2} \mathrm{C}_{3} \mathrm{~N}$, is predicted to be produced in the same reaction at least twice more efficiently than $\mathrm{CH}_{2} \mathrm{C}_{3} \mathrm{~N}$. Hence, $\mathrm{HC}_{3} \mathrm{HCN}$ is a plausible candidate to be observed in space as well.

Aims. We aim to generate the $\mathrm{HC}_{3} \mathrm{HCN}$ radical in the gas phase in order to investigate its rotational spectrum. The derived spectroscopic parameters for this species will be used to obtain reliable frequency predictions to support its detection in space.

Methods. The $\mathrm{HC}_{3} \mathrm{HCN}$ radical was produced by an electric discharge, and its rotational spectrum was characterized using a BalleFlygare narrowband-type Fourier-transform microwave spectrometer operating in the frequency region of 4-40 GHz. The spectral analysis was supported by high-level ab initio calculations.

Results. A total of 193 hyperfine components that originated from 12 rotational transitions, $a$ - and $b$-type, were measured for the $\mathrm{HC}_{3} \mathrm{HCN}$ radical. The analysis allowed us to accurately determine 22 molecular constants, including rotational and centrifugal distortion constants as well as the fine and hyperfine constants. Transition frequency predictions were used to search for the $\mathrm{HC}_{3} \mathrm{HCN}$ radical in TMC-1 using the QUIJOTE survey between 30 and $50 \mathrm{GHz}$. We do not detect $\mathrm{HC}_{3} \mathrm{HCN}$ in TMC-1 and derive a $3 \sigma$ upper limit to its column density of $6.0 \times 10^{11} \mathrm{~cm}^{-2}$.
\end{abstract}

Key words. astrochemistry - ISM: molecules - ISM: individual objects: TMC-1 - methods: laboratory: molecular molecular processes

\section{Introduction}

The radioastronomical discovery of new molecules in space is highly dependent on the availability of precise rotational spectroscopic laboratory data. Only a few molecular species have been detected in space prior to their characterization in the laboratory. Some examples of this type are $\mathrm{HCO}^{+}(\mathrm{Buhl} \&$ Snyder 1970), $\mathrm{C}_{4} \mathrm{H}$ (Gúelin et al. 1978), $\mathrm{HCS}^{+}$(Thaddeus et al. 1981), $\mathrm{C}_{5} \mathrm{H}$ (Cernicharo et al. 1986), $\mathrm{C}_{6} \mathrm{H}$ (Suzuki et al. 1986), and $\mathrm{C}_{3} \mathrm{H}^{+}$(Pety et al. 2012). All of them were confirmed later on in the laboratory. Other cases such as $\mathrm{C}_{5} \mathrm{~N}^{-}$(Cernicharo et al. 2008), $\mathrm{MgC}_{3} \mathrm{~N}$ and $\mathrm{MgC}_{4} \mathrm{H}$ (Cernicharo et al. 2019), $\mathrm{HC}_{5} \mathrm{NH}^{+}$ (Marcelino et al. 2020), $\mathrm{MgC}_{5} \mathrm{~N}$ and $\mathrm{MgC}_{6} \mathrm{H}$ (Pardo et al. 2021), and $\mathrm{H}_{2} \mathrm{NC}$ (Cabezas et al. 2021a) have not been yet observed in the laboratory. Although most of these molecules are openshell species, they display almost trivial spectral patterns, except for $\mathrm{H}_{2} \mathrm{NC}$. These patterns allowed their identifications in the line

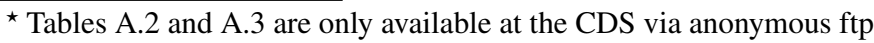
to cdsarc.u-strasbg. fr (130.79.128.5) or via http://cdsarc. u-strasbg.fr/viz-bin/cat/J/A+A/657/A24

$\star \star$ Based on observations carried out with the Yebes $40 \mathrm{~m}$ telescope (projects 19A003, 20A014, and 20D15). The $40 \mathrm{~m}$ radiotelescope at Yebes Observatory is operated by the Spanish Geographic Institute (IGN, Ministerio de Transportes, Movilidad y Agenda Urbana).
}

surveys only supported by dedicated ab initio calculations. However, other interstellar molecules and potential candidates have much more complex rotational spectra due to the presence of two or three nuclei with nonzero nuclear spins, which causes complicated line splitting by interactions of different types of angular momenta. In these cases, ab initio calculations are not enough to identify their spectral features in the line surveys, and the laboratory experiments are invaluable tools (Cabezas et al. 2021c).

An example of this type of open-shell species is the 3-cyano propargyl radical, $\mathrm{CH}_{2} \mathrm{C}_{3} \mathrm{~N}$, which was recently discovered in space (Cabezas et al. 2021b). Its astronomical identification was possible through high-resolution laboratory experiments (Chen et al. 1998; Tang et al. 2001), which provided frequency predictions with an accuracy better than $10 \mathrm{kHz}$ in the $30-50 \mathrm{GHz}$ region. The hyperfine components for seven rotational transitions of $\mathrm{CH}_{2} \mathrm{C}_{3} \mathrm{~N}$ were detected in the cold dark cloud TMC-1 using the Yebes $40 \mathrm{~m}$ telescope. The matching of these precise frequencies to interstellar features was then aided by the sharpness of the radio emission features in TMC-1, around $40 \mathrm{kHz}$ at $40 \mathrm{GHz}$

One of the routes to form $\mathrm{CH}_{2} \mathrm{C}_{3} \mathrm{~N}$ in space is the reaction $\mathrm{C}+\mathrm{CH}_{2} \mathrm{CHCN} \rightarrow \mathrm{CH}_{2} \mathrm{C}_{3} \mathrm{~N}+\mathrm{H}$. This reaction has been studied using crossed molecular beam experiments and theoretical calculations (Su et al. 2005; Guo et al. 2006). These studies indicate 
that the reaction is barrierless and occurs through $\mathrm{H}$ atom elimination, yielding as main products the radicals 3-cyano propargyl $\left(\mathrm{CH}_{2} \mathrm{C}_{3} \mathrm{~N}\right)$ and its isomer 1-cyano propargyl $\left(\mathrm{HC}_{3} \mathrm{HCN}\right)$. The latter is inferred to be produced at least twice more efficiently than the former (Guo et al. 2006), and thus, it is a good candidate for detection in TMC-1 as well.

As far as we could ascertain from the literature, no spectroscopic work on 1-cyano propargyl radical $\left(\mathrm{HC}_{3} \mathrm{HCN}\right)$ has been published so far. The only information about this species is that mentioned previously about crossed molecular beam experiments and theoretical calculations ( $\mathrm{Su}$ et al. 2005; Guo et al. 2006). In the present work, we report the first rotational study of $\mathrm{HC}_{3} \mathrm{HCN}$ using Fourier transform microwave (FTMW) spectroscopy supported by ab initio calculations. In addition, we carried out an astronomical search of $\mathrm{HC}_{3} \mathrm{HCN}$ in TMC-1 using accurate frequency predictions derived from our spectroscopic study.

\section{Experiment}

The rotational spectrum of the $\mathrm{HC}_{3} \mathrm{HCN}$ radical was observed using a Balle-Flygare narrowband-type FTMW spectrometer operating in the frequency region of $4-40 \mathrm{GHz}$ (Endo et al. 1994; Cabezas et al. 2016). The short-lived species $\mathrm{HC}_{3} \mathrm{HCN}$ was produced in a supersonic expansion by a pulsed electric discharge of a gas mixture of $\mathrm{CH}_{2} \mathrm{CHCN}(0.2 \%)$ and $\mathrm{C}_{2} \mathrm{H}_{2}(0.4 \%)$ diluted in Ar. This gas mixture was flowed through a pulsedsolenoid valve that is accommodated in the backside of one of the cavity mirrors and aligned parallel to the optical axis of the resonator. A pulse voltage of $900 \mathrm{~V}$ with a duration of $450 \mu$ s was applied between stainless-steel electrodes attached to the exit of the pulsed discharge nozzle (PDN), resulting in an electric discharge synchronized with the gas expansion. The resulting products generated in the discharge were supersonically expanded, rapidly cooled to a rotational temperature of $\sim 2.5 \mathrm{~K}$ between the two mirrors of the Fabry-Pérot resonator, and then probed by FTMW spectroscopy. For measurements of the paramagnetic lines, the Earth's magnetic field was cancelled by using three sets of Helmholtz coils placed perpendicularly to one another. Since the PDN is arranged parallel to the cavity of the spectrometer, it is possible to suppress the Doppler broadening of the spectral lines, which allows resolving small hyperfine splittings. The spectral resolution is $5 \mathrm{kHz}$, and the frequency measurements have an estimated accuracy better than $3 \mathrm{kHz}$.

\section{Ab initio calculations}

The geometry optimization calculation of $\mathrm{HC}_{3} \mathrm{HCN}$ was carried out using the spin-restricted coupled cluster method with single, double, and perturbative triple excitations (RCCSD $(T)$; Raghavachari et al. 1989) with all electrons (valence and core) correlated and the Dunning correlation-consistent basis sets with polarized core-valence correlation quadruple- $\zeta$ (ccpCVQZ; Woon \& Dunning 1995). At the optimized geometry, electric dipole moment components along the $a$ - and $b$-inertial axes were calculated at the same level of theory as that for the geometrical optimization. The calculations were performed using the MOLPRO 2020.2 program (Werner et al. 2020). The fine and hyperfine coupling constants of the $\mathrm{HC}_{3} \mathrm{HCN}$ radical were estimated at the second-order Møller-Plesset perturbation (MP2; Møller \& Plesset 1934) and the quadratic configuration interaction with single- and double-excitation (QCISD; Pople et al. 1987) levels of calculations, with the cc-pVTZ basis set (Woon \& Dunning 1995). Harmonic frequencies were computed
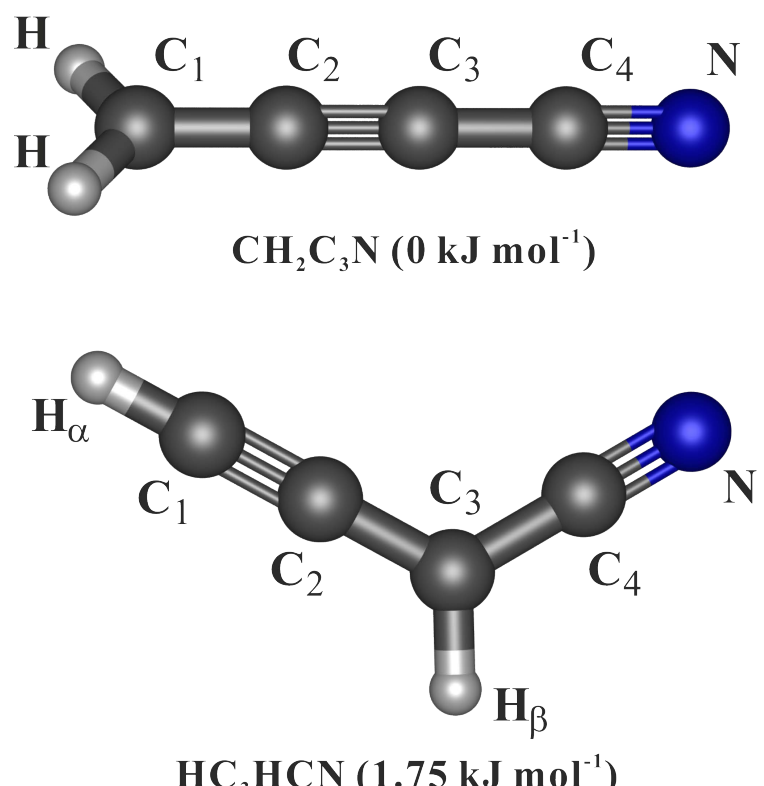

Fig. 1. Molecular structures and relative energies of the $\mathrm{CH}_{2} \mathrm{C}_{3} \mathrm{~N}$ and $\mathrm{HC}_{3} \mathrm{HCN}$ radicals.

at the MP2/cc-pVTZ level of theory to estimate the centrifugal distortion constants. These calculations were performed using the Gaussian16 (Frisch et al. 2016) program package. The calculated geometry of $\mathrm{HC}_{3} \mathrm{HCN}$ in the ${ }^{2} A^{\prime \prime}$ ground electronic state is depicted in Fig. 1 together with that for the $\mathrm{CH}_{2} \mathrm{C}_{3} \mathrm{~N}$ isomer. The calculated molecular parameters and the dipole moment components are summarized in Table 1.

In addition, we carried out optimization calculations for the $\mathrm{CH}_{2} \mathrm{C}_{3} \mathrm{~N}$ isomer in order to ascertain the relative energies of this species and $\mathrm{HC}_{3} \mathrm{HCN}$. The RCCSD(T)/cc-pCVQZ energies with the zeropoint energy corrections at RCCSD/cc-VQZ level of theory indicate that the $\mathrm{CH}_{2} \mathrm{C}_{3} \mathrm{~N}$ isomer is slightly more stable than $\mathrm{HC}_{3} \mathrm{HCN}$ by $1.75 \mathrm{~kJ} \mathrm{~mol}^{-1}$. Su et al. (2005) carried out quantum chemical calculations for $\mathrm{HC}_{3} \mathrm{HCN}$ and $\mathrm{CH}_{2} \mathrm{C}_{3} \mathrm{~N}$ isomers at the B3LYP/6-311G(d,p)//CCSD(T)/6-311G(d,p) level of theory. They found that $\mathrm{CH}_{2} \mathrm{C}_{3} \mathrm{~N}$ is more stable by $14.9 \mathrm{~kJ} \mathrm{~mol}^{-1}$ when B3LYP/6-311G(d,p) energies are taken into account. However, $\mathrm{HC}_{3} \mathrm{HCN}$ is $2.1 \mathrm{~kJ} \mathrm{~mol}^{-1}$ more stable than $\mathrm{CH}_{2} \mathrm{C}_{3} \mathrm{~N}$ if the $\operatorname{CCSD}(\mathrm{T}) / 6-311 \mathrm{G}(\mathrm{d}, \mathrm{p})$ energies are considered. Given the small energy differences, which are of the order of the error of the calculations, we can consider that the two isomers $\mathrm{CH}_{2} \mathrm{C}_{3} \mathrm{~N}$ and $\mathrm{HC}_{3} \mathrm{HCN}$ are nearly isoenergetic.

\section{Rotational spectrum analysis}

The predicted $a$-type dipole moment for the $\mathrm{HC}_{3} \mathrm{HCN}$ radical is $3.70 \mathrm{D}$, and thus, the $a$-type rotational transitions are expected to be fairly strong. Hence, we first tried to observe this type of transition. In particular, we searched for the $N_{K_{a} K_{c}}=20,2-$ $1_{0,1}$ transition, which is predicted around $10.8 \mathrm{GHz}$. A group of more than 20 paramagnetic lines were observed in the $10.7 \mathrm{GHz}$ region. The $3_{0,3}-2_{0,2}, 4_{0,4}-3_{0,3}$, and $5_{0,5}-4_{0,4}$ transitions were then searched around 16.1, 21.5, and $26.8 \mathrm{GHz}$. Three groups of paramagnetic lines with a similar spectral pattern to that observed in the $10.7 \mathrm{GHz}$ region were found around these frequencies. Figure 2 shows the recorded spectra for the $a$-type $K_{a}=0$ rotational transitions. The $\mathrm{HC}_{3} \mathrm{HCN}$ radical was readily confirmed as the spectral carrier based on the following arguments. (i) The observed transition frequencies agree well 
Table 1. Spectroscopic parameters of $\mathrm{HC}_{3} \mathrm{HCN}$ (all in $\mathrm{MHz}$ ).

\begin{tabular}{lcc}
\hline \hline Parameter & Experimental & Theoretical \\
\hline$A$ & $29173.01440(72)^{(a)}$ & $27909^{(b)}$ \\
$B$ & $2807.94534(25)$ & $2835^{(b)}$ \\
$C$ & $2556.92917(25)$ & $2574^{(b)}$ \\
$\Delta_{N}$ & $0.0014120(19)$ & $0.0014^{(c)}$ \\
$\Delta_{N K}$ & $-0.109826(50)$ & $-0.091^{(c)}$ \\
$\delta_{N}$ & $0.0003574(45)$ & $0.000345^{(c)}$ \\
$\varepsilon_{a a}$ & $-60.5224(30)$ & $-51.35^{(c)}$ \\
$\varepsilon_{b b}$ & $-5.3817(12)$ & $-6.385^{(c)}$ \\
$\varepsilon_{c c}$ & $-0.5405(13)$ & $-1.60^{(c)}$ \\
$\varepsilon_{a b}$ & $\mp 1.214(73)^{(d)}$ & $\mp 1.64^{(c)}$ \\
$a_{F}{ }^{\left(\mathrm{H}_{\alpha}\right)}$ & $-32.2969(32)$ & $-31.70^{(e)}$ \\
$T_{a a}{ }^{\left(\mathrm{H}_{\alpha}\right)}$ & $8.7599(36)$ & $9.14^{(e)}$ \\
$T_{b b}{ }^{\left(\mathrm{H}_{\alpha}\right)}$ & $-7.9786(61)$ & $-8.43^{(e)}$ \\
$T_{a b}{ }^{\left(\mathrm{H}_{\alpha}\right)}$ & $\pm 12.58(20)^{(d)}$ & $\pm 13.55^{(e)}$ \\
$a_{F}{ }^{\left(\mathrm{H}_{\beta}\right)}$ & $-51.3475(46)$ & $-55.10^{(e)}$ \\
$T_{a a}{ }^{\left(\mathrm{H}_{\beta}\right)}$ & $-25.3318(27)$ & $-29.31^{(e)}$ \\
$T_{b b}{ }^{\left(\mathrm{H}_{\beta}\right)}$ & $24.5181(48)$ & $28.42^{(e)}$ \\
$T_{a b}{ }^{\left(\mathrm{H}_{\beta}\right)}$ & {$[ \pm 0.79]^{(f)}$} & $\pm 0.79^{(e)}$ \\
$a_{F}{ }^{(\mathrm{N})}$ & $6.6999(27)$ & $1.1852^{(e)}$ \\
$T_{a a}{ }^{(\mathrm{N})}$ & $-10.3977(22)$ & $-11.33^{(e)}$ \\
$T_{b b}{ }^{(\mathrm{N})}$ & $-9.1827(48)$ & $-9.51^{(e)}$ \\
$T_{a b}{ }^{(\mathrm{N})}$ & {$[ \pm 1.72]$} & $\pm 1.72^{(e)}$ \\
$\chi_{a a}{ }^{(\mathrm{N})}$ & $-2.7743(22)$ & $-2.82^{(e)}$ \\
$\chi_{b b}{ }^{(\mathrm{N})}$ & $0.6098(42)$ & $0.57^{(e)}$ \\
$\chi_{a b}{ }^{(\mathrm{N})}$ & {$[ \pm 2.70]$} & $\pm 2.70^{(e)}$ \\
\hline$\left|\mu_{a}\right|$ & & $3.70^{(b, g)}$ \\
$\left|\mu_{b}\right|$ & & $1.77^{(b, g)}$ \\
\hline${ }^{(e)}$ &
\end{tabular}

Notes. ${ }^{(a)}$ Numbers in parentheses are $1 \sigma$ uncertainties in units of the last digits. ${ }^{(b)} \mathrm{RCCSD}(\mathrm{T}) / \mathrm{cc}-\mathrm{pCVQZ} .{ }^{(c)} \mathrm{MP} 2 / \mathrm{cc}-\mathrm{pVTZ} .{ }^{\left({ }^{(d)}\right.}$ Only the relative signs are determined. ${ }^{(e)} \mathrm{QCISD} / \mathrm{cc}-\mathrm{pVTZ} .{ }^{(f)}$ Values in brackets were fixed to the theoretical values. ${ }^{\left({ }^{g}\right)}$ In units of Debye.

with the calculated frequencies, (ii) each transition has a hyperfine spectral structure similar to that expected for an open-shell species with three coupling nuclei, and (iii) the lines exhibit the paramagnetic behavior.

The hyperfine components for these four transitions were analyzed using an appropriate Hamiltonian for an asymmetric top molecule with a doublet electronic state $\left({ }^{2} A^{\prime \prime}\right)$ and the centrifugal distortion expressed in Watson's $A$-reduced form (Watson 1967). The employed Hamiltonian has the following form:

$\mathbf{H}=\mathbf{H}_{\mathrm{rot}}+\mathbf{H}_{\mathrm{sr}}+\mathbf{H}_{\mathrm{mhf}}+\mathbf{H}_{Q}$,

where $\mathbf{H}_{\text {rot }}$ contains rotational and centrifugal distortion parameters, $\mathbf{H}_{\mathrm{sr}}$ is the spin-rotation term, $\mathbf{H}_{\mathrm{mhf}}$ represents the magnetic hyperfine coupling interaction term due to the hydrogen and nitrogen nuclei, and $\mathbf{H}_{\mathrm{Q}}$ represents the nuclear electric quadrupole interaction due to the nitrogen nucleus. A complete description of these terms can be found in Hirota (1985). The coupling scheme used is $\mathbf{J}=\mathbf{N}+\mathbf{S}, \mathbf{F}_{1}=\mathbf{J}+\mathbf{I}_{1}, \mathbf{F}_{2}=\mathbf{F}_{1}+\mathbf{I}_{2}$, and $\mathbf{F}=\mathbf{F}_{2}+\mathbf{I}_{3}$, where $\mathbf{I}_{1}=\mathbf{I}\left(\mathrm{H}_{\beta}\right), \mathbf{I}_{2}=\mathbf{I}\left(\mathrm{H}_{\alpha}\right)$ and $\mathbf{I}_{3}=\mathbf{I}(\mathrm{N})$.

An initial fit to the $K_{a}=0$ transition frequencies provided a first set of experimental constants for $\mathrm{HC}_{3} \mathrm{HCN}$, which was later on refined. The following assignment was performed in a classical bootstrap manner, where assigned transitions were used to improve the frequency predictions and to search for new ones. In this manner, we measured six $K_{a}=1 a$-type transitions with $N=2,3$, and 4 and two $b$-type $Q$-branch transitions, $1_{1,0}-1_{0,1}$ and $2_{1,1}-2_{0,2}$. The final dataset consists of 193 hyperfine components that originated from 12 rotational transitions. Table A.1 contains the experimental and calculated frequencies for all the observed hyperfine components as well as their relative intensities within a particular rotational transition, normalized to the degeneracy of the lower level. Twenty-two molecular constants were determined by the least-squares analysis for all the observed transition frequencies. The standard deviation of the fit is $2.0 \mathrm{kHz}$, which is slightly smaller than the experimental accuracy of the measurements, indicating that the complicated hyperfine structures caused by the three nuclei are well described by the employed Hamiltonian. The determined molecular constants are summarized in Table 1 along with those predicted by ab initio calculations.

\section{Discussion}

As mentioned before, a total of 22 molecular constants were determined from the fit. For 2 of them, $\varepsilon_{a b}$ and $T_{a b}{ }^{\left(\mathrm{H}_{\alpha}\right)}$, only the relative signs could be determined. In addition to these 22 parameters, we included in the fit 3 parameters, $T_{a b}{ }^{\left(\mathrm{H}_{\beta}\right)}, T_{a b}{ }^{(\mathrm{N})}$, and $\chi_{a b}{ }^{(\mathrm{N})}$, fixed to the theoretical values. This resulted in an improvement of the standard deviation of the fit from $2.4 \mathrm{kHz}$ to the final deviation of $2.0 \mathrm{kHz}$. In general, Table 1 shows that the experimentally determined values agree well with the ab initio ones, which implies that the calculated molecular structure is reasonable. The $B$ and $C$ calculated constants show relative errors from the experimental values of 0.7 and $0.9 \%$, respectively. In contrast, the relative error for the $A$ constant is fairly large, around $4.3 \%$. We tried to reproduce the experimental value of the $A$ constant by increasing the level of calculation, but no better results were found. We also considered that this discrepancy could be due to the vibrational contribution. However, our vibration-rotation calculations showed that this contribution is not that large, it is smaller than $0.5 \%$.

If scaled by the rotational constants, the spin-rotation interaction constants determined for $\mathrm{HC}_{3} \mathrm{HCN}$ are similar to those for the $\mathrm{CH}_{2} \mathrm{C}_{3} \mathrm{~N}$ isomer, as shown in Table 2. The $A, B$, and $C$ constants for $\mathrm{CH}_{2} \mathrm{C}_{3} \mathrm{~N}$ are $288000,2195.08395$, and 2177.77590 $\mathrm{MHz}$, respectively (Tang et al. 2001). This implies that the two radicals have a nearly equal-energy excited states, ${ }^{2} B_{2}$ in the case of $\mathrm{CH}_{2} \mathrm{C}_{3} \mathrm{~N}$ and ${ }^{2} A^{\prime}$ for $\mathrm{HC}_{3} \mathrm{HCN}$, which contribute mainly to the spin-rotation interaction constants in the ground state through the spin-orbit coupling. The Fermi coupling constants give direct information of the unpaired electron density on the nuclei. The $a_{F}{ }^{\left(\mathrm{H}_{\alpha}\right)}$ and $a_{F}{ }^{\left(\mathrm{H}_{\beta}\right)}$ have negative values due to the spin-polarization in the $\mathrm{C}-\mathrm{H}$ bonds. The difference in the absolute values between $a_{F}{ }^{\left(\mathrm{H}_{\alpha}\right)}$ and $a_{F}{ }^{\left(\mathrm{H}_{\beta}\right)}$ indicate that the unpaired electron density in $\mathrm{C}_{1}$ is lower than that in $\mathrm{C}_{3}$. This is consistent with the predictions of the molecular structure and the unpaired electron orbital depicted in Fig. 3.

As shown in Table 2, the $a_{F}{ }^{\left(\mathrm{H}_{\beta}\right)}$ value is very similar to that found for the hydrogen nuclei of $\mathrm{CH}_{2} \mathrm{C}_{3} \mathrm{~N}$. Hence, it can be inferred that the unpaired electron density in $\mathrm{C}_{1}$ of $\mathrm{CH}_{2} \mathrm{C}_{3} \mathrm{~N}$ is very much like that in $\mathrm{C}_{3}$ of $\mathrm{HC}_{3} \mathrm{HCN}$, which is illustrated in Fig. 3. As for the nitrogen nucleus, the $a_{F}$ constant is almost similar in $\mathrm{HC}_{3} \mathrm{HCN}$ and $\mathrm{CH}_{2} \mathrm{C}_{3} \mathrm{~N}$. On the other hand, the determined $T_{a a}$ and $T_{b b}$ constants for the nitrogen nucleus in $\mathrm{HC}_{3} \mathrm{HCN}$ are very similar and roughly satisfy the relation $T_{c c}=-2 T_{a a}=-2 T_{b b}$. This indicates that the orientation of the unpaired electron is along the $c$-axis and occupies a $p_{\pi}$ molecular orbital extending perpendicular to the molecular plane. This is shown in Fig. 3. 

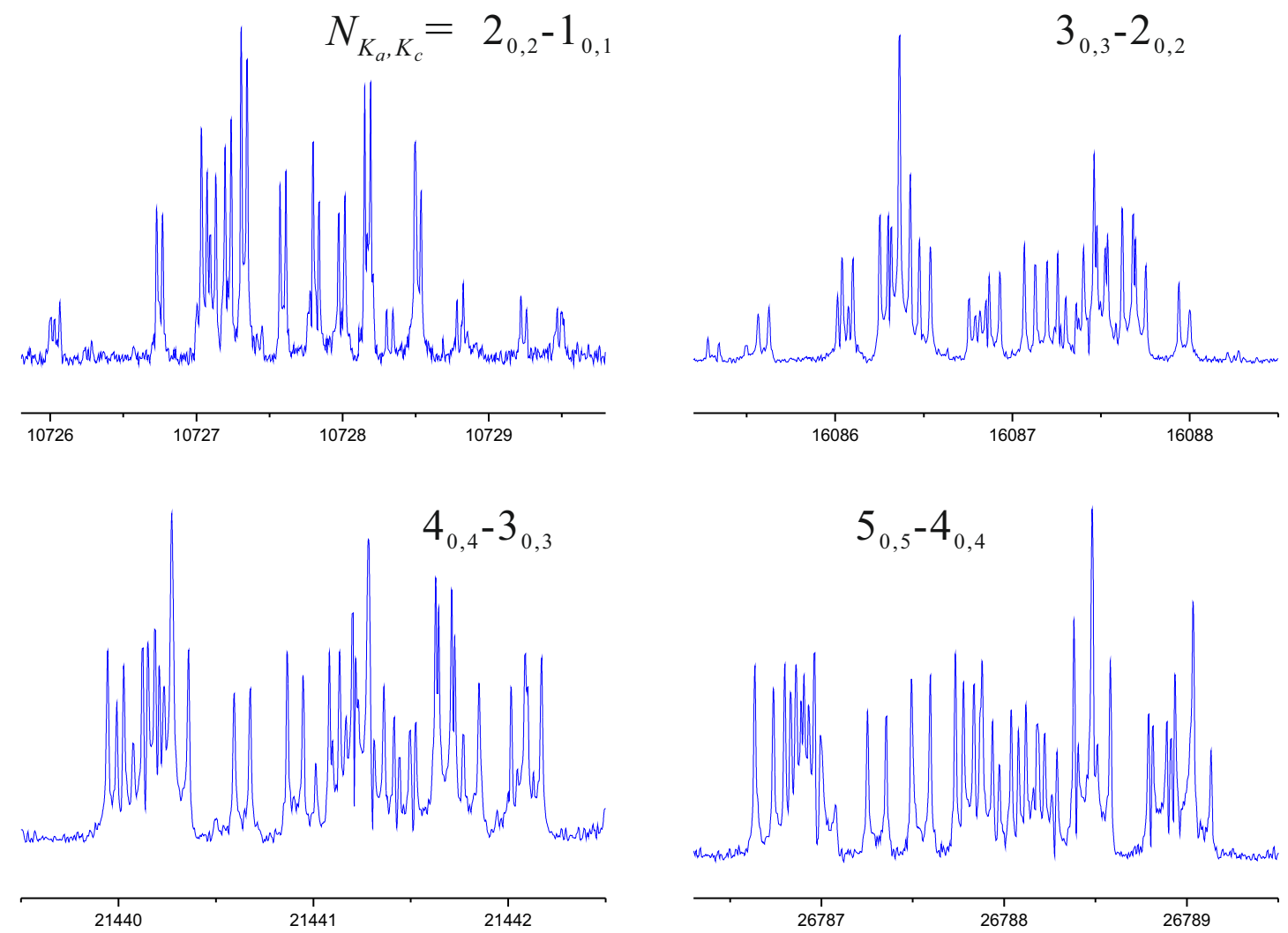

Fig. 2. Four $K_{a}=0 a$-type rotational transitions for the $\mathrm{HC}_{3} \mathrm{HCN}$ radical. For the $2_{0,2}-1_{0,1}, 3_{0,3}-2_{0,2}$, and $4_{0,4}-3_{0,3}$ transitions, additional hyperfine components, which are not shown in this figure, were also observed. The abscissa corresponds to the frequency of the lines in MHz. The spectra were achieved by 100 shots of accumulation and a step scan of $0.5 \mathrm{MHz}$ with a repetition rate of $10 \mathrm{~Hz}$. The coaxial arrangement of the adiabatic expansion and the resonator axis produces an instrumental Doppler doubling. The resonance frequencies are calculated as the average of the two Doppler components.

Table 2. Spin-rotation interaction, Fermi coupling, and dipole-dipole constants for $\mathrm{HC}_{3} \mathrm{HCN}$ and $\mathrm{CH}_{2} \mathrm{C}_{3} \mathrm{~N}$ (all in $\mathrm{MHz}$ ).

\begin{tabular}{lcc}
\hline \hline Parameter & $\mathrm{HC}_{3} \mathrm{HCN}$ & $\mathrm{CH}_{2} \mathrm{C}_{3} \mathrm{~N}$ \\
\hline$\varepsilon_{a a}$ & -60.5224 & -660.330 \\
$\varepsilon_{b b}$ & -5.3817 & -4.2396 \\
$\varepsilon_{c c}$ & -0.5405 & -0.3955 \\
$a_{F}\left(\mathrm{H}_{\alpha}\right)$ & -32.2969 & $-50.69^{(a)}$ \\
$a_{F}\left(\mathrm{H}_{\beta}\right)$ & -51.3475 & $-50.69^{(a)}$ \\
$a_{F}(\mathrm{~N})$ & 6.6999 & 5.1618 \\
$T_{a a}(\mathrm{~N})$ & -10.3977 & -8.2149 \\
$T_{b b}{ }^{(\mathrm{N})}$ & -9.1827 & -5.362 \\
\hline
\end{tabular}

Notes. ${ }^{(a)}$ The notation $\left(\mathrm{H}_{\alpha}\right)$ and $\left(\mathrm{H}_{\beta}\right)$ does not apply to $\mathrm{CH}_{2} \mathrm{C}_{3} \mathrm{~N}$.

The values for $T_{a a}$ and $T_{b b}$ in both $\mathrm{HC}_{3} \mathrm{HCN}$ and $\mathrm{CH}_{2} \mathrm{C}_{3} \mathrm{~N}$ radicals are comparable, which indicates that the unpaired electron density around the nitrogen nucleus in both radicals is almost the same. All these facts reveal similarities between the ground states of both radicals.

Three canonical forms can be used to describe the $\mathrm{HC}_{3} \mathrm{HCN}$ radical: $\mathrm{H}-\mathrm{C} \equiv \mathrm{C}-\dot{\mathrm{C}} \mathrm{H}-\mathrm{C} \equiv \mathrm{N}, \mathrm{H}-\dot{\mathrm{C}}=\mathrm{C}=\mathrm{CH}-\mathrm{C} \equiv \mathrm{N}$, and $\mathrm{H}-\mathrm{C} \equiv \mathrm{C}-$ $\mathrm{CH}=\mathrm{C}=\dot{\mathrm{N}}$. The calculated bond lengths for $\mathrm{HC}_{3} \mathrm{HCN}$ are $1.217 \AA, 1.385 \AA, 1.407 \AA$, and $1.164 \AA$ for $\mathrm{C}_{1}-\mathrm{C}_{2}, \mathrm{C}_{2}-\mathrm{C}_{3}$, $\mathrm{C}_{3}-\mathrm{C}_{4}$, and $\mathrm{C}_{4}-\mathrm{N}$, respectively. The bond distances $\mathrm{C}_{1}-\mathrm{C}_{2}$ and $\mathrm{C}_{4}-\mathrm{N}$ are almost identical to those found in the molecule $\mathrm{HC}_{3} \mathrm{~N}$ (Botschwina et al. 1993), $1.206 \AA$ and $1.161 \AA$ for $\mathrm{C}-\mathrm{C}$ and

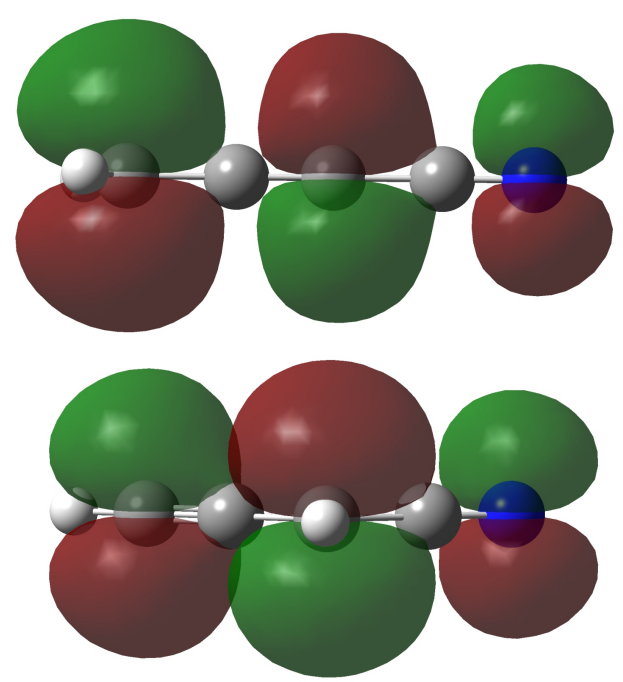

Fig. 3. Molecular orbital for the unpaired electron in $\mathrm{CH}_{2} \mathrm{C}_{3} \mathrm{~N}$ (top) and $\mathrm{HC}_{3} \mathrm{HCN}$ (bottom).

$\mathrm{C}-\mathrm{N}$ triple bonds, respectively. The $\mathrm{C}_{2}-\mathrm{C}_{3}$ and $\mathrm{C}_{3}-\mathrm{C}_{4}$ lengths are slightly larger than the $\mathrm{C}-\mathrm{C}$ single-bond distance in $\mathrm{HC}_{3} \mathrm{~N}$. Although the three Lewis structures are contributing to the electronic structure for the ${ }^{2} A^{\prime \prime}$ ground state, the ab initio geometry indicates that the $\mathrm{H}-\mathrm{C} \equiv \mathrm{C}-\dot{\mathrm{C}} \mathrm{H}-\mathrm{C} \equiv \mathrm{N}$ form contributes slightly more than the other two. This agrees with the molecular orbital of the unpaired electron for $\mathrm{HC}_{3} \mathrm{HCN}$ shown in Fig. 3 and the values determined for the Fermi constants. 
Table 3. Rotational partition function for $\mathrm{HC}_{3} \mathrm{HCN}$ at different temperatures.

\begin{tabular}{cc}
\hline \hline Temperature/K & $Q_{r}$ \\
\hline 300.000 & 694460.4 \\
225.000 & 559886.3 \\
150.000 & 388347.4 \\
75.000 & 175077.8 \\
37.500 & 66626.2 \\
18.750 & 24000.2 \\
10.000 & 9495.6 \\
9.375 & 8634.1 \\
\hline
\end{tabular}

\section{Astronomical search}

From the spectroscopic parameters presented in Table 1, we generated reliable frequency predictions to guide the astronomical search for $\mathrm{HC}_{3} \mathrm{HCN}$. The predictions have an accuracy better than $10 \mathrm{kHz}$ in the $Q$ band $(30-50 \mathrm{GHz})$ and $\sim 10-20 \mathrm{kHz}$ in the $\mathrm{W}$ band $(72-116 \mathrm{GHz})$. The rotational partition functions we used in these predictions are listed in Table 3. They were calculated considering a maximum value of $N=40$. The frequency predictions for $\mathrm{HC}_{3} \mathrm{HCN}$ up to $300 \mathrm{GHz}$ calculated at $T=10$ and $300 \mathrm{~K}$ are available at the CDS, Tables A.2 and A.3 respectively.

We searched for the $\mathrm{HC}_{3} \mathrm{HCN}$ radical toward the cold dark molecular cloud TMC-1, where the $\mathrm{CH}_{2} \mathrm{C}_{3} \mathrm{~N}$ isomer has been detected (Cabezas et al. 2021b). The spectral data employed in this work are part of the QUIJOTE ${ }^{1}$ line survey (Cernicharo et al. 2021a), performed toward TMC-1 $\left(\alpha_{J 2000}=4^{\mathrm{h}} 41^{\mathrm{m}} 41.9^{\mathrm{s}}\right.$ and $\left.\delta_{J 2000}=+25^{\circ} 41^{\prime} 27.0^{\prime \prime}\right)$ in the $Q$ band using the Yebes $40 \mathrm{~m}$ radiotelescope. The observations were performed in three different observing runs during November 2019 and April 2021. The first observing run allowed the detection of the $\mathrm{C}_{3} \mathrm{~N}^{-}$ and $\mathrm{C}_{5} \mathrm{~N}^{-}$anions (Cernicharo et al. 2020a) and the discoveries of $\mathrm{HC}_{4} \mathrm{NC}$ (Cernicharo et al. 2020b), $\mathrm{HC}_{3} \mathrm{O}^{+}$(Cernicharo et al. 2020c), and $\mathrm{HC}_{5} \mathrm{NH}^{+}$(Marcelino et al. 2020). Sensitivity improvements from additional observations performed in October 2020 resulted in the detection of HDCCN (Cabezas et al. 2021c), $\mathrm{HC}_{3} \mathrm{~S}^{+}$(Cernicharo et al. 2021b), and $\mathrm{CH}_{3} \mathrm{CO}^{+}$ (Cernicharo et al. 2021b) and three isomers with the formula $\mathrm{C}_{4} \mathrm{H}_{3} \mathrm{~N}$ (Marcelino et al. 2021). The last observing run performed between December 2020 and April 2021 resulted in new discoveries, including hydrocarbon species such as the $\mathrm{CH}_{2} \mathrm{CCH}$ radical (Agúndez et al. 2021a), $\mathrm{CH}_{2} \mathrm{CHCCH}$ and $\mathrm{CH}_{2} \mathrm{CCHCCH}$ (Cernicharo et al. 2021d,e), $l-\mathrm{H}_{2} \mathrm{C}_{5}$ (Cabezas et al. 2021d), $c-\mathrm{C}_{3} \mathrm{HCCH}, c-\mathrm{C}_{5} \mathrm{H}_{6}$, and $c-\mathrm{C}_{9} \mathrm{H}_{8}$ (Cernicharo et al. 2021f); sulphur-bearing species such as NCS, HCCS, $\mathrm{H}_{2} \mathrm{CCS}, \mathrm{H}_{2} \mathrm{CCCS}, \mathrm{C}_{4} \mathrm{~S}, \mathrm{HCSCN}$, and $\mathrm{HCSCCH}$ (Cernicharo et al. 2021g,h); O-bearing complex organic molecules such as $\mathrm{C}_{2} \mathrm{H}_{3} \mathrm{CHO}, \mathrm{C}_{2} \mathrm{H}_{3} \mathrm{OH}, \mathrm{HCOOCH}_{3}$, and $\mathrm{CH}_{3} \mathrm{OCH}_{3}$ (Agúndez et al. 2021b), and deuterated isotopologs such as $\mathrm{CH}_{2} \mathrm{DC}_{3} \mathrm{~N}$ (Cabezas et al. 2021e).

All observations were carried out using the frequencyswitching technique, with a frequency throw of $10 \mathrm{MHz}$ during the first two observing runs and a throw of $8 \mathrm{MHz}$ in the later ones. The intensity scale, the antenna temperature $T_{\mathrm{A}}^{*}$, was calibrated using two absorbers at different temperatures and the atmospheric transmission model (ATM; Cernicharo 1985; Pardo et al. 2001). Different frequency coverages were observed, 31.08-49.52 GHz and 31.98-50.42 GHz, which permit

\footnotetext{
$1 Q$-band Ultrasensitive Inspection Journey to the Obscure TMC-1 Environment.
}
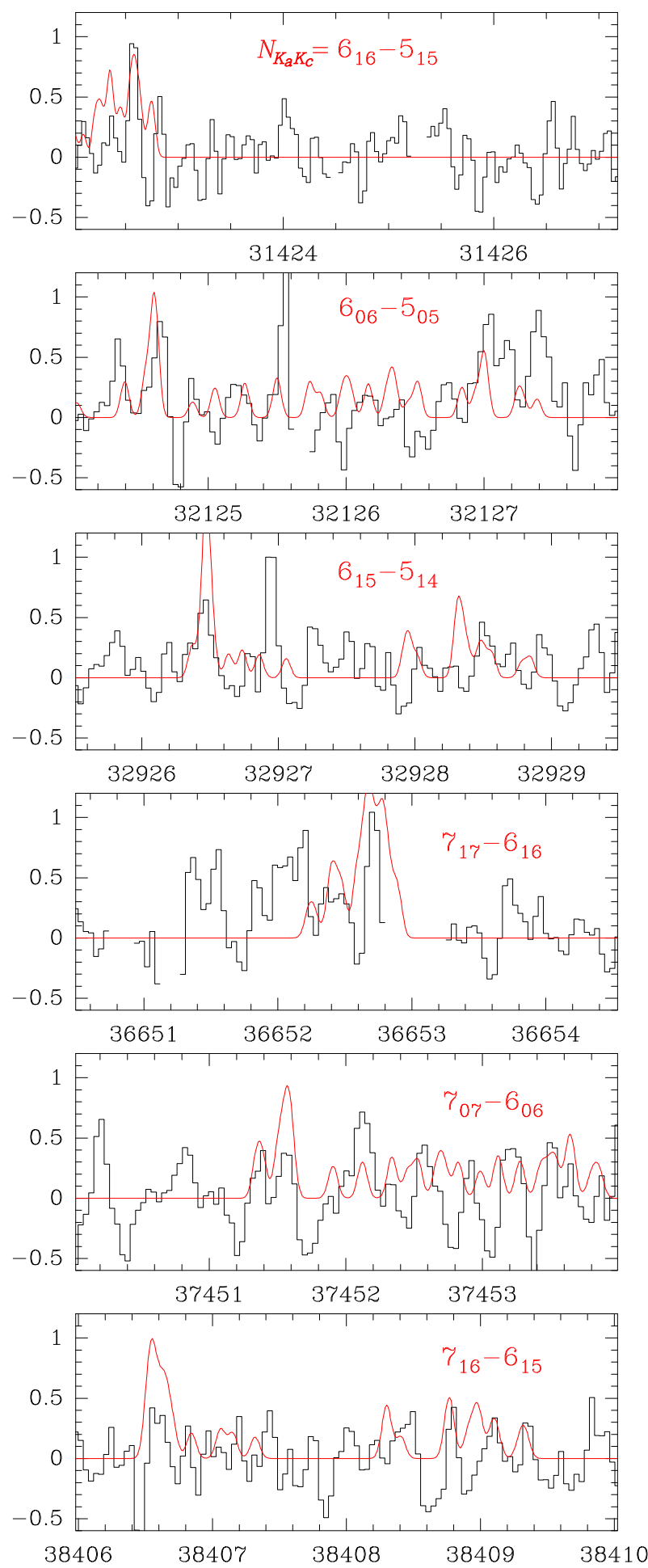

Fig. 4. Observed data of TMC-1 from the QUIJOTE line survey (black histogram) and synthetic spectra calculated adopting as column density the upper limit given in the text (red curve). For each rotational transition, the most intense hyperfine components are shown. The abscissa corresponds to the rest frequency assuming a local standard of rest velocity of $5.83 \mathrm{~km} \mathrm{~s}^{-1}$. The ordinate is the antenna temperature in millikelvin.

verifying that no spurious ghosts are produced in the downconversion chain in which the signal coming from the receiver is downconverted to $1-19.5 \mathrm{GHz}$ and then split into eight bands with a coverage of $2.5 \mathrm{GHz}$, each of which are analyzed by the FFTs. Calibration uncertainties were adopted to be $10 \%$ based 
on the observed repeatability of the line intensities between different observing runs. All data were analyzed using the GILDAS package $^{2}$

The frequency predictions were implemented in the MADEX code (Cernicharo 2012) to compute synthetic spectra assuming local thermodynamic equilibrium. We used the dipole moment components from Table 1 and assumed a rotational temperature of $7 \mathrm{~K}$ (Cabezas et al. 2021b) and a $v_{\mathrm{LSR}}=5.83 \mathrm{~km} \mathrm{~s}^{-1}$ (Cernicharo et al. 2020a). Figure 4 shows the spectrum of TMC1 at the frequencies of selected transitions of $\mathrm{HC}_{3} \mathrm{HCN}$, together with the synthetic spectra calculated with MADEX. Lines of $\mathrm{HC}_{3} \mathrm{HCN}$ are not clearly seen in our TMC-1 data. The sensitivity of the QUIJOTE line survey varies between 0.17 and $0.3 \mathrm{mK}$ in the $31-50 \mathrm{GHz}$ domain. Adopting the observed $3 \sigma$ limits to the intensity of strongest components of $\mathrm{HC}_{3} \mathrm{HCN}$, we derive a $3 \sigma$ upper limit to the column density of this species in TMC-1 of $6.0 \times 10^{11} \mathrm{~cm}^{-2}$.

Given the column density of $\mathrm{CH}_{2} \mathrm{C}_{3} \mathrm{~N}$ in TMC-1, $1.6 \times$ $10^{11} \mathrm{~cm}^{-2}$ (Cabezas et al. 2021b), the column density ratio between the two isomers $\mathrm{HC}_{3} \mathrm{HCN} / \mathrm{CH}_{2} \mathrm{C}_{3} \mathrm{~N}$ is $<3.8$. This means that even if $\mathrm{HC}_{3} \mathrm{HCN}$ is not detected, it could still be more abundant than $\mathrm{CH}_{2} \mathrm{C}_{3} \mathrm{~N}$. The nonobservation of the $\mathrm{HC}_{3} \mathrm{HCN}$ radical can be explained by the large partition function for $\mathrm{HC}_{3} \mathrm{HCN}$ compared to that for $\mathrm{CH}_{2} \mathrm{C}_{3} \mathrm{~N}$. For example, the partition function at $10 \mathrm{~K}$ for $\mathrm{HC}_{3} \mathrm{HCN}$ is 9462 , while that for ortho- $\mathrm{CH}_{2} \mathrm{C}_{3} \mathrm{~N}$ is 1718 . Hence, the expected intensity of the lines of $\mathrm{HC}_{3} \mathrm{HCN}$, assuming the same column density as for $\mathrm{CH}_{2} \mathrm{C}_{3} \mathrm{~N}$, will be much lower, which makes its detection more difficult. The chemistry of $\mathrm{CH}_{2} \mathrm{C}_{3} \mathrm{~N}$ in TMC-1 has been discussed by Cabezas et al. (2021b). The main formation reactions are $\mathrm{C}+\mathrm{CH}_{2} \mathrm{CHCN}$, $\mathrm{C}_{2}+\mathrm{CH}_{3} \mathrm{CN}, \mathrm{CN}+\mathrm{CH}_{2} \mathrm{CCH}$, and $\mathrm{CH}_{3} \mathrm{C}_{3} \mathrm{NH}^{+}+\mathrm{e}^{-}$. The beststudied of these reactions is $\mathrm{C}+\mathrm{CH}_{2} \mathrm{CHCN}$ (Su et al. 2005; Guo et al. 2006). Theoretical calculations predict that in this reaction $\mathrm{HC}_{3} \mathrm{HCN}$ is formed five times faster than $\mathrm{CH}_{2} \mathrm{C}_{3} \mathrm{~N}$ ( $\mathrm{Su}$ et al. 2005), while crossed-beam experiments also favor $\mathrm{HC}_{3} \mathrm{HCN}$ as the main product, at least twice more than $\mathrm{CH}_{2} \mathrm{C}_{3} \mathrm{~N}$ (Guo et al. 2006). It is still necessary to study the other potential routes to these radicals mentioned above. However, if the reaction $\mathrm{C}+$ $\mathrm{CH}_{2} \mathrm{CHCN}$ is one of the dominant routes to $\mathrm{CH}_{2} \mathrm{C}_{3} \mathrm{~N}$ in TMC-1, as suggested by the chemical model presented by Cabezas et al. (2021b), and if this reaction produces $\mathrm{HC}_{3} \mathrm{HCN}$ with an even higher branching ratio than $\mathrm{CH}_{2} \mathrm{C}_{3} \mathrm{~N}$, it is likely that a deeper integration will lead to the detection of the $\mathrm{HC}_{3} \mathrm{HCN}$ radical in TMC-1. This will also allow us to better constrain the formation routes to these radicals and their role as intermediates in the buildup of large organic molecules in cold dark clouds.

\section{Conclusion}

We report the investigation of the rotational spectrum of 1-cyano propargyl radical, $\mathrm{HC}_{3} \mathrm{HCN}$. This transient species was generated in the gas phase using an electric discharges technique and was then characterized by Fourier transform microwave spectroscopy. A total of 193 hyperfine components that originated from 12 rotational transitions were observed and analyzed with $a^{2} A^{\prime \prime}$ Hamiltonian. Accurate values for 22 molecular constants were derived from the analysis, indicating that the complicated hyperfine structures caused by the three nuclei with nonzero nuclear spin are well described by the employed Hamiltonian. The values of the hyperfine constants for the hydrogen and nitrogen nuclei were compared to those found for the $\mathrm{CH}_{2} \mathrm{C}_{3} \mathrm{~N}$

\footnotetext{
2 http://www.iram.fr/IRAMFR/GILDAS
}

isomer, and it seems that both radicals share some electronic similarities. Reliable frequency predictions were obtained from the molecular parameters derived from the spectroscopic analysis. These predictions were used to search for $\mathrm{HC}_{3} \mathrm{HCN}$ in TMC-1 using the QUIJOTE line survey. We cannot confirm the presence of $\mathrm{HC}_{3} \mathrm{HCN}$ in TMC-1, but we obtained a $3 \sigma$ upper limit to its column density of $6.0 \times 10^{11} \mathrm{~cm}^{-2}$.

Acknowledgements. The Spanish authors thank ERC for funding through grant ERC-2013-Syg-610256-NANOCOSMOS and Ministerio de Ciencia e Innovación for funding support through projects PID2019-106235GB-I00 and PID2019-107115GB-C21 / AEI / 10.13039/501100011033. M.A. thanks Ministerio de Ciencia e Innovación for grant RyC-2014-16277. Y.E. thanks Ministry of Science and Technology of Taiwan through grant MOST108-2113-M-009-25.

\section{References}

Agúndez, M., \& Wakelam, V. 2013, Chem. Rev., 113, 8710 Agúndez, M., Marcelino, N., \& Cernicharo, J., et al. 2018, ApJ, 861, L22 Agúndez, M., Cabezas, C., Tercero, B., et al. 2021a, A\&A, 647, L10 Agúndez, M., Marcelino, N., Tercero, B., et al. 2021b, A\&A, 649, L4 Botschwina, P., Horn, M., Seeger, S., \& Flügge, J. 1993. Mol. Phys., 78, 191 Buhl, D., \& Snyder, L. E. 1970, Nature, 228, 267

Cabezas, C., Guillemin, J.-C., \& Endo, Y. 2016, J. Chem. Phys., 145, 184304 Cabezas, C., Agúndez, M., Marcelino, N., et al. 2021a, A\&A, 654, A45 Cabezas, C., Agúndez, M., Marcelino, N., et al. 2021b, A\&A, 654, L9 Cabezas, C., Endo, Y., Roueff, E., et al. 2021c, A\&A, 646, L1

Cabezas, C., Tercero, B., Agúndez, M., et al. 2021d, A\&A, 650, L9 Cabezas, C., Roueff, E., Tercero, B., et al. 2021e, A\&A, 650, L15 Chen, W., McCarthy, M. C., Travers, M. J., et al. 1998, ApJ, 492, 849 Cernicharo, J. 1985, Internal IRAM Report (Granada: IRAM) Cernicharo, J. 2012, EAS Pub. Ser., 58, 251

Cernicharo, J., Kahane, C., Gómez-González, J., \& Guélin, M. 1986, A\&A, 167, L5

Cernicharo, J., Guélin, M., Agúndez, M., et al. 2008, ApJ, 688, L83 Cernicharo, J., Cabezas, C., Pardo, J. R., et al. 2019, A\&A, 630, L2 Cernicharo, J., Marcelino, N., Pardo, J. R., et al. 2020a, A\&A, 641, L9 Cernicharo, J., Marcelino, N., Agúndez, M., et al. 2020b, A\&A, 642, L8 Cernicharo, J., Marcelino, N., Agúndez, M., et al. 2020c, A\&A, 642, L17 Cernicharo, J., Agúndez, M., Kaiser, R., et al. 2021a, A\&A, 652, L9 Cernicharo, J., Cabezas, C., Endo, Y., et al. 2021b, A\&A, 646, L3 Cernicharo, J., Cabezas, C., Bailleux, S., et al. 2021c, A\&A, 646, L7 Cernicharo, J., Agúndez, M., Cabezas, C., et al. 2021d, A\&A, 647, L2 Cernicharo, J., Cabezas, C., Agúndez, M., et al. 2021e, A\&A, 647, L3 Cernicharo, J., Agúndez, M., Cabezas, C., et al. 2021f, A\&A, 649, L15 Cernicharo, J., Cabezas, C., Agúndez, M., et al. 2021g, A\&A, 648, L3 Cernicharo, J., Cabezas, C., Agúndez, M., et al. 2021h, A\&A, 650, L14 Endo, Y., Kohguchi, H., \& Ohshima, Y. 1994, Faraday Discuss., 97, 341 Frisch, M. J., Trucks, G. W., Schlegel, H. B., et al. 2016, Gaussian 16 Revision A.03

Guélin, M., Green, S., \& Thaddeus, P. 1978, ApJ, 224, L27

Guo, Y., Gu, X., Zhang, F., et al. 2006, PCCP, 8, 5454

Hirota, E. 1985, High-Resolution Spectroscopy of Transient Molecules (Berlin: Springer-Verlag)

Marcelino, N., Agúndez, M., Tercero, B., et al. 2020, A\&A, 643, L6

Marcelino, N., Tercero, B., Agúndez, M., \& Cernicharo, J. 2021, A\&A, 646, L9 McGuire, B. A. 2018, ApJS, 239, 17

McGuire, B. A., Burkhardt, A. M., Kalenskii, S., et al. 2018, Science, 359, 202 Møller, C., \& Plesset, M. S. 1934, Phys. Rev., 46, 618

Pardo, J. R., Cernicharo, J., Serabyn, E. 2001, IEEE Trans. Antennas and Propagation, 49, 12

Pardo, J. R., Bermúdez, C., Cabezas, C. et al., 2020 A\&A, 640, L13

Pardo, J. R., Cabezas, C., Fonfría, J. P., et al. 2021, A\&A, 652, L13

Pety, J., Gratier, P., Guzmán, V., et al. 2012, A\&A, 548, A68

Pople, J. A., Head-Gordon, M., \& Raghavachari, K. 1987, J. Chem. Phys., 87, 5968

Raghavachari, K., Trucks, G. W., Pople, J. A., \& Head-Gordon, M. 1989, Chem. Phys. Lett., 157, 479

Su, H.-F., Kaiser, R. I., \& Chang, A. H. H. 2005, J. Chem. Phys., 122, 074320

Suzuki, H., Ohishi, M., Kaifu, N., et al. 1986, PASJ, 38, 911

Tang, J., Sumiyoshi, Y., \& Endo, Y. 2001, ApJ, 492, 552, 409

Thaddeus, P., Guélin, M., \& Linke, R. A. 1981, ApJ, 246, L41

Watson, J. K. G. 1967, J. Chem. Phys. 46, 1935

Werner, H.-J., Knowles, P. J., Knizia, G., et al. 2020, MOLPRO, version 2020.2

Woon, D. E., \& Dunning, T. H. 1995, J. Chem. Phys., 103, 4572 
C. Cabezas et al.: Laboratory detection of $\mathrm{HC}_{3} \mathrm{HCN}$

Appendix A: Laboratory observed transition frequencies for $\mathrm{HC}_{3} \mathrm{HCN}$ 
Table A.1. Observed transition frequencies for $\mathrm{HC}_{3} \mathrm{HCN}$.

\begin{tabular}{|c|c|c|c|c|c|c|c|c|c|c|c|c|c|c|c|c|c|}
\hline$\overline{N^{\prime}}$ & $K_{a}^{\prime}$ & $K_{c}^{\prime}$ & $J^{\prime}$ & $F_{1}^{\prime}$ & $F_{2}^{\prime}$ & $F^{\prime}$ & $N^{\prime \prime}$ & $K_{a}^{\prime \prime}$ & $K_{c}^{\prime \prime}$ & $J^{\prime \prime}$ & $F_{1}^{\prime \prime}$ & $F_{2}^{\prime \prime}$ & $F^{\prime \prime}$ & $\begin{array}{c}v_{o b s} \\
(\mathrm{MHz})\end{array}$ & $\begin{array}{c}v_{\text {calc }} \\
(\mathrm{MHz})\end{array}$ & $\begin{array}{c}\text { Obs-Calc } \\
(\mathrm{MHz})\end{array}$ & Int. $^{a}$ \\
\hline 2 & 1 & 2 & 1.5 & 2.0 & 2.5 & 2.5 & 1 & 1 & 1 & 0.5 & 1.0 & 1.5 & 1.5 & 10470.944 & 10470.945 & -0.001 & 1.368 \\
\hline 2 & 1 & 2 & 1.5 & 2.0 & 2.5 & 3.5 & 1 & 1 & 1 & 0.5 & 1.0 & 1.5 & 2.5 & 10472.128 & 10472.128 & -0.000 & 2.269 \\
\hline 2 & 1 & 2 & 2.5 & 3.0 & 2.5 & 3.5 & 1 & 1 & 1 & 1.5 & 1.0 & 1.5 & 2.5 & 10479.894 & 10479.894 & -0.000 & 1.420 \\
\hline 2 & 1 & 2 & 2.5 & 3.0 & 3.5 & 3.5 & 1 & 1 & 1 & 1.5 & 2.0 & 2.5 & 2.5 & 10483.322 & 10483.322 & 0.000 & 2.123 \\
\hline 2 & 1 & 2 & 2.5 & 3.0 & 3.5 & 4.5 & 1 & 1 & 1 & 1.5 & 2.0 & 2.5 & 3.5 & 10486.000 & 10486.001 & -0.001 & 2.994 \\
\hline 2 & 1 & 2 & 2.5 & 3.0 & 2.5 & 3.5 & 1 & 1 & 1 & 1.5 & 2.0 & 1.5 & 2.5 & 10491.230 & 10491.229 & 0.001 & 0.963 \\
\hline 2 & 0 & 2 & 2.5 & 2.0 & 2.5 & 3.5 & 1 & 0 & 1 & 1.5 & 2.0 & 2.5 & 3.5 & 10721.774 & 10721.774 & -0.000 & 1.069 \\
\hline 2 & 0 & 2 & 1.5 & 1.0 & 1.5 & 1.5 & 1 & 0 & 1 & 0.5 & 0.0 & 0.5 & 0.5 & 10722.410 & 10722.410 & 0.000 & 0.623 \\
\hline 2 & 0 & 2 & 1.5 & 1.0 & 1.5 & 2.5 & 1 & 0 & 1 & 0.5 & 1.0 & 1.5 & 1.5 & 10724.395 & 10724.393 & 0.002 & 1.509 \\
\hline 2 & 0 & 2 & 1.5 & 2.0 & 1.5 & 2.5 & 1 & 0 & 1 & 0.5 & 0.0 & 0.5 & 1.5 & 10724.419 & 10724.421 & -0.002 & 0.914 \\
\hline 2 & 0 & 2 & 2.5 & 2.0 & 1.5 & 1.5 & 1 & 0 & 1 & 1.5 & 1.0 & 0.5 & 1.5 & 10725.576 & 10725.575 & 0.001 & 0.699 \\
\hline 2 & 0 & 2 & 2.5 & 2.0 & 2.5 & 2.5 & 1 & 0 & 1 & 1.5 & 2.0 & 2.5 & 2.5 & 10726.048 & 10726.048 & 0.000 & 0.467 \\
\hline 2 & 0 & 2 & 2.5 & 3.0 & 3.5 & 2.5 & 1 & 0 & 1 & 1.5 & 2.0 & 2.5 & 1.5 & 10726.750 & 10726.750 & 0.000 & 2.279 \\
\hline 2 & 0 & 2 & 2.5 & 3.0 & 3.5 & 3.5 & 1 & 0 & 1 & 1.5 & 2.0 & 2.5 & 2.5 & 10727.055 & 10727.055 & 0.000 & 2.803 \\
\hline 2 & 0 & 2 & 2.5 & 3.0 & 2.5 & 2.5 & 1 & 0 & 1 & 1.5 & 2.0 & 1.5 & 1.5 & 10727.110 & 10727.113 & -0.003 & 2.013 \\
\hline 2 & 0 & 2 & 2.5 & 3.0 & 2.5 & 3.5 & 1 & 0 & 1 & 1.5 & 2.0 & 1.5 & 2.5 & 10727.218 & 10727.218 & 0.000 & 3.175 \\
\hline 2 & 0 & 2 & 2.5 & 3.0 & 3.5 & 4.5 & 1 & 0 & 1 & 1.5 & 2.0 & 2.5 & 3.5 & 10727.328 & 10727.326 & 0.002 & 4.000 \\
\hline 2 & 0 & 2 & 2.5 & 2.0 & 1.5 & 2.5 & 1 & 0 & 1 & 1.5 & 1.0 & 0.5 & 1.5 & 10727.593 & 10727.593 & 0.000 & 1.657 \\
\hline 2 & 0 & 2 & 1.5 & 2.0 & 2.5 & 2.5 & 1 & 0 & 1 & 1.5 & 1.0 & 1.5 & 1.5 & 10727.819 & 10727.818 & 0.001 & 2.331 \\
\hline 2 & 0 & 2 & 2.5 & 2.0 & 2.5 & 2.5 & 1 & 0 & 1 & 0.5 & 1.0 & 0.5 & 1.5 & 10727.996 & 10727.995 & 0.001 & 1.611 \\
\hline 2 & 0 & 2 & 1.5 & 2.0 & 2.5 & 3.5 & 1 & 0 & 1 & 1.5 & 1.0 & 1.5 & 2.5 & 10728.172 & 10728.173 & -0.001 & 3.199 \\
\hline 2 & 0 & 2 & 2.5 & 2.0 & 1.5 & 2.5 & 1 & 0 & 1 & 1.5 & 1.0 & 1.5 & 2.5 & 10728.324 & 10728.322 & 0.002 & 0.673 \\
\hline 2 & 0 & 2 & 2.5 & 2.0 & 2.5 & 3.5 & 1 & 0 & 1 & 0.5 & 1.0 & 1.5 & 2.5 & 10728.517 & 10728.517 & 0.000 & 1.759 \\
\hline 2 & 0 & 2 & 2.5 & 2.0 & 1.5 & 1.5 & 1 & 0 & 1 & 1.5 & 1.0 & 0.5 & 0.5 & 10728.804 & 10728.802 & 0.002 & 0.784 \\
\hline 2 & 0 & 2 & 1.5 & 2.0 & 1.5 & 0.5 & 1 & 0 & 1 & 0.5 & 1.0 & 0.5 & 0.5 & 10729.240 & 10729.240 & 0.000 & 0.601 \\
\hline 2 & 0 & 2 & 2.5 & 2.0 & 1.5 & 0.5 & 1 & 0 & 1 & 1.5 & 1.0 & 0.5 & 0.5 & 10729.491 & 10729.493 & -0.002 & 0.524 \\
\hline 2 & 0 & 2 & 1.5 & 2.0 & 1.5 & 2.5 & 1 & 0 & 1 & 0.5 & 1.0 & 1.5 & 2.5 & 10730.484 & 10730.484 & 0.000 & 1.045 \\
\hline 2 & 0 & 2 & 1.5 & 2.0 & 1.5 & 1.5 & 1 & 0 & 1 & 0.5 & 1.0 & 0.5 & 1.5 & 10731.401 & 10731.399 & 0.002 & 0.485 \\
\hline 2 & 0 & 2 & 1.5 & 1.0 & 0.5 & 1.5 & 1 & 0 & 1 & 0.5 & 0.0 & 0.5 & 1.5 & 10732.834 & 10732.837 & -0.003 & 0.631 \\
\hline 2 & 1 & 1 & 2.5 & 2.0 & 2.5 & 3.5 & 1 & 1 & 0 & 1.5 & 1.0 & 1.5 & 2.5 & 10970.762 & 10970.763 & -0.001 & 1.362 \\
\hline 2 & 1 & 1 & 1.5 & 2.0 & 2.5 & 3.5 & 1 & 1 & 0 & 0.5 & 1.0 & 1.5 & 2.5 & 10972.811 & 10972.812 & -0.001 & 2.241 \\
\hline 2 & 1 & 1 & 1.5 & 2.0 & 2.5 & 2.5 & 1 & 1 & 0 & 0.5 & 1.0 & 1.5 & 1.5 & 10973.887 & 10973.886 & 0.001 & 1.523 \\
\hline 2 & 1 & 1 & 2.5 & 3.0 & 2.5 & 3.5 & 1 & 1 & 0 & 1.5 & 1.0 & 1.5 & 2.5 & 10979.876 & 10979.875 & 0.001 & 0.488 \\
\hline 2 & 1 & 1 & 2.5 & 3.0 & 2.5 & 2.5 & 1 & 1 & 0 & 1.5 & 1.0 & 1.5 & 1.5 & 10981.327 & 10981.329 & -0.002 & 0.905 \\
\hline 2 & 1 & 1 & 2.5 & 3.0 & 3.5 & 2.5 & 1 & 1 & 0 & 1.5 & 2.0 & 2.5 & 1.5 & 10984.470 & 10984.462 & 0.008 & 1.706 \\
\hline 2 & 1 & 1 & 2.5 & 3.0 & 3.5 & 3.5 & 1 & 1 & 0 & 1.5 & 2.0 & 2.5 & 2.5 & 10984.571 & 10984.572 & -0.001 & 2.320 \\
\hline 2 & 1 & 1 & 2.5 & 3.0 & 3.5 & 4.5 & 1 & 1 & 0 & 1.5 & 2.0 & 2.5 & 3.5 & 10985.861 & 10985.863 & -0.002 & 2.997 \\
\hline 2 & 1 & 1 & 2.5 & 3.0 & 2.5 & 3.5 & 1 & 1 & 0 & 1.5 & 2.0 & 1.5 & 2.5 & 10987.152 & 10987.152 & 0.000 & 1.892 \\
\hline 2 & 1 & 1 & 2.5 & 3.0 & 2.5 & 2.5 & 1 & 1 & 0 & 1.5 & 2.0 & 1.5 & 1.5 & 10987.651 & 10987.652 & -0.001 & 0.629 \\
\hline 3 & 1 & 3 & 2.5 & 3.0 & 2.5 & 2.5 & 2 & 1 & 2 & 1.5 & 2.0 & 1.5 & 1.5 & 15712.568 & 15712.567 & 0.001 & 1.747 \\
\hline 3 & 1 & 3 & 2.5 & 2.0 & 2.5 & 3.5 & 2 & 1 & 2 & 1.5 & 1.0 & 1.5 & 2.5 & 15712.920 & 15712.919 & 0.001 & 1.772 \\
\hline 3 & 1 & 3 & 2.5 & 3.0 & 2.5 & 3.5 & 2 & 1 & 2 & 1.5 & 2.0 & 1.5 & 2.5 & 15713.285 & 15713.284 & 0.001 & 2.801 \\
\hline 3 & 1 & 3 & 2.5 & 3.0 & 3.5 & 3.5 & 2 & 1 & 2 & 1.5 & 2.0 & 2.5 & 2.5 & 15715.069 & 15715.070 & -0.001 & 2.741 \\
\hline 3 & 1 & 3 & 3.5 & 3.0 & 3.5 & 4.5 & 2 & 1 & 2 & 2.5 & 2.0 & 2.5 & 3.5 & 15716.388 & 15716.388 & -0.000 & 3.269 \\
\hline 3 & 1 & 3 & 3.5 & 3.0 & 3.5 & 3.5 & 2 & 1 & 2 & 2.5 & 3.0 & 2.5 & 2.5 & 15716.600 & 15716.600 & -0.000 & 2.422 \\
\hline 3 & 1 & 3 & 3.5 & 3.0 & 2.5 & 3.5 & 2 & 1 & 2 & 2.5 & 2.0 & 1.5 & 2.5 & 15718.283 & 15718.281 & 0.002 & 2.859 \\
\hline 3 & 1 & 3 & 3.5 & 4.0 & 4.5 & 3.5 & 2 & 1 & 2 & 2.5 & 3.0 & 3.5 & 2.5 & 15718.819 & 15718.819 & -0.000 & 2.827 \\
\hline 3 & 1 & 3 & 3.5 & 4.0 & 3.5 & 3.5 & 2 & 1 & 2 & 2.5 & 2.0 & 2.5 & 2.5 & 15719.133 & 15719.134 & -0.001 & 2.259 \\
\hline 3 & 1 & 3 & 3.5 & 4.0 & 4.5 & 4.5 & 2 & 1 & 2 & 2.5 & 3.0 & 3.5 & 3.5 & 15719.421 & 15719.421 & -0.000 & 3.545 \\
\hline 3 & 1 & 3 & 3.5 & 4.0 & 3.5 & 4.5 & 2 & 1 & 2 & 2.5 & 3.0 & 2.5 & 3.5 & 15719.921 & 15719.920 & 0.001 & 3.761 \\
\hline 3 & 1 & 3 & 3.5 & 4.0 & 4.5 & 5.5 & 2 & 1 & 2 & 2.5 & 3.0 & 3.5 & 4.5 & 15720.414 & 15720.413 & 0.001 & 4.569 \\
\hline 3 & 0 & 3 & 3.5 & 3.0 & 3.5 & 4.5 & 2 & 0 & 2 & 2.5 & 3.0 & 3.5 & 4.5 & 16081.880 & 16081.880 & 0.000 & 0.701 \\
\hline 3 & 0 & 3 & 2.5 & 2.0 & 1.5 & 1.5 & 2 & 0 & 2 & 1.5 & 1.0 & 0.5 & 0.5 & 16084.905 & 16084.905 & -0.000 & 0.580 \\
\hline 3 & 0 & 3 & 3.5 & 3.0 & 2.5 & 2.5 & 2 & 0 & 2 & 2.5 & 2.0 & 1.5 & 2.5 & 16085.313 & 16085.314 & -0.001 & 0.520 \\
\hline 3 & 0 & 3 & 2.5 & 2.0 & 1.5 & 2.5 & 2 & 0 & 2 & 1.5 & 1.0 & 0.5 & 1.5 & 16085.596 & 16085.596 & 0.000 & 1.481 \\
\hline 3 & 0 & 3 & 3.5 & 4.0 & 3.5 & 2.5 & 2 & 0 & 2 & 2.5 & 3.0 & 2.5 & 1.5 & 16086.044 & 16086.047 & -0.003 & 2.182 \\
\hline 3 & 0 & 3 & 3.5 & 4.0 & 4.5 & 3.5 & 2 & 0 & 2 & 2.5 & 3.0 & 3.5 & 2.5 & 16086.070 & 16086.069 & 0.001 & 3.315 \\
\hline 3 & 0 & 3 & 3.5 & 4.0 & 4.5 & 4.5 & 2 & 0 & 2 & 2.5 & 3.0 & 3.5 & 3.5 & 16086.285 & 16086.282 & 0.003 & 4.191 \\
\hline 3 & 0 & 3 & 3.5 & 4.0 & 3.5 & 4.5 & 2 & 0 & 2 & 2.5 & 3.0 & 2.5 & 3.5 & 16086.331 & 16086.331 & -0.000 & 4.267 \\
\hline 3 & 0 & 3 & 3.5 & 4.0 & 4.5 & 5.5 & 2 & 0 & 2 & 2.5 & 3.0 & 3.5 & 4.5 & 16086.393 & 16086.393 & 0.000 & 5.143 \\
\hline 3 & 0 & 3 & 3.5 & 4.0 & 3.5 & 3.5 & 2 & 0 & 2 & 2.5 & 3.0 & 2.5 & 2.5 & 16086.507 & 16086.506 & 0.001 & 3.184 \\
\hline 3 & 0 & 3 & 3.5 & 3.0 & 3.5 & 2.5 & 2 & 0 & 2 & 2.5 & 2.0 & 2.5 & 1.5 & 16086.787 & 16086.784 & 0.003 & 2.138 \\
\hline 3 & 0 & 3 & 2.5 & 2.0 & 2.5 & 2.5 & 2 & 0 & 2 & 1.5 & 1.0 & 1.5 & 1.5 & 16086.820 & 16086.823 & -0.003 & 1.912 \\
\hline 3 & 0 & 3 & 2.5 & 3.0 & 2.5 & 3.5 & 2 & 0 & 2 & 1.5 & 2.0 & 1.5 & 2.5 & 16086.900 & 16086.898 & 0.002 & 2.326 \\
\hline 3 & 0 & 3 & 3.5 & 3.0 & 3.5 & 3.5 & 2 & 0 & 2 & 2.5 & 2.0 & 2.5 & 2.5 & 16087.099 & 16087.098 & 0.001 & 2.828 \\
\hline 3 & 0 & 3 & 3.5 & 3.0 & 2.5 & 3.5 & 2 & 0 & 2 & 2.5 & 2.0 & 1.5 & 2.5 & 16087.226 & 16087.227 & -0.001 & 2.868 \\
\hline 3 & 0 & 3 & 3.5 & 3.0 & 2.5 & 2.5 & 2 & 0 & 2 & 2.5 & 2.0 & 1.5 & 1.5 & 16087.331 & 16087.331 & -0.000 & 2.019 \\
\hline 3 & 0 & 3 & 3.5 & 3.0 & 3.5 & 4.5 & 2 & 0 & 2 & 2.5 & 2.0 & 2.5 & 3.5 & 16087.432 & 16087.432 & 0.000 & 3.523 \\
\hline 3 & 0 & 3 & 2.5 & 3.0 & 2.5 & 2.5 & 2 & 0 & 2 & 1.5 & 2.0 & 1.5 & 1.5 & 16087.494 & 16087.497 & -0.003 & 1.811 \\
\hline 3 & 0 & 3 & 2.5 & 3.0 & 3.5 & 3.5 & 2 & 0 & 2 & 1.5 & 2.0 & 2.5 & 2.5 & 16087.505 & 16087.505 & 0.000 & 3.237 \\
\hline 3 & 0 & 3 & 2.5 & 3.0 & 3.5 & 4.5 & 2 & 0 & 2 & 1.5 & 2.0 & 2.5 & 3.5 & 16087.651 & 16087.651 & -0.000 & 4.284 \\
\hline 3 & 0 & 3 & 2.5 & 2.0 & 2.5 & 3.5 & 2 & 0 & 2 & 1.5 & 1.0 & 1.5 & 2.5 & 16087.723 & 16087.723 & 0.000 & 2.988 \\
\hline 3 & 0 & 3 & 2.5 & 3.0 & 3.5 & 2.5 & 2 & 0 & 2 & 1.5 & 2.0 & 2.5 & 1.5 & 16087.971 & 16087.970 & 0.001 & 2.279 \\
\hline
\end{tabular}


Table A.1. continued.

\begin{tabular}{|c|c|c|c|c|c|c|c|c|c|c|c|c|c|c|c|c|c|}
\hline$\overline{N^{\prime}}$ & $K_{a}^{\prime}$ & $K_{c}^{\prime}$ & $J^{\prime}$ & $F_{1}^{\prime}$ & $F_{2}^{\prime}$ & $F^{\prime}$ & $N^{\prime \prime}$ & $K_{a}^{\prime \prime}$ & $K_{c}^{\prime \prime}$ & $J^{\prime \prime}$ & $F_{1}^{\prime \prime}$ & $F_{2}^{\prime \prime}$ & $F^{\prime \prime}$ & $\begin{array}{c}v_{o b s} \\
(\mathrm{MHz})\end{array}$ & $\begin{array}{c}v_{\text {calc }} \\
(\mathrm{MHz})\end{array}$ & $\begin{array}{c}\text { Obs-Calc } \\
(\mathrm{MHz})\end{array}$ & Int. $^{a}$ \\
\hline 3 & 0 & 3 & 3.5 & 3.0 & 2.5 & 1.5 & 2 & 0 & 2 & 2.5 & 2.0 & 1.5 & 1.5 & 16088.246 & 16088.249 & -0.003 & 0.372 \\
\hline 3 & 0 & 3 & 2.5 & 3.0 & 2.5 & 3.5 & 2 & 0 & 2 & 2.5 & 2.0 & 2.5 & 3.5 & 16088.864 & 16088.865 & -0.001 & 0.869 \\
\hline 3 & 0 & 3 & 2.5 & 2.0 & 1.5 & 0.5 & 2 & 0 & 2 & 1.5 & 1.0 & 0.5 & 0.5 & 16089.521 & 16089.518 & 0.003 & 0.618 \\
\hline 3 & 0 & 3 & 2.5 & 3.0 & 2.5 & 2.5 & 2 & 0 & 2 & 2.5 & 2.0 & 2.5 & 2.5 & 16090.897 & 16090.901 & -0.004 & 0.345 \\
\hline 3 & 0 & 3 & 2.5 & 2.0 & 1.5 & 1.5 & 2 & 0 & 2 & 1.5 & 1.0 & 0.5 & 1.5 & 16091.982 & 16091.983 & -0.001 & 0.725 \\
\hline 3 & 1 & 2 & 2.5 & 2.0 & 2.5 & 3.5 & 2 & 1 & 1 & 1.5 & 1.0 & 1.5 & 2.5 & 16467.119 & 16467.119 & 0.000 & 2.692 \\
\hline 3 & 1 & 2 & 2.5 & 2.0 & 1.5 & 2.5 & 2 & 1 & 1 & 1.5 & 1.0 & 0.5 & 1.5 & 16467.347 & 16467.346 & 0.001 & 1.426 \\
\hline 3 & 1 & 2 & 3.5 & 3.0 & 3.5 & 4.5 & 2 & 1 & 1 & 2.5 & 2.0 & 2.5 & 3.5 & 16467.658 & 16467.659 & -0.001 & 3.171 \\
\hline 3 & 1 & 2 & 3.5 & 3.0 & 3.5 & 3.5 & 2 & 1 & 1 & 2.5 & 2.0 & 2.5 & 2.5 & 16468.581 & 16468.581 & -0.000 & 2.440 \\
\hline 3 & 1 & 2 & 3.5 & 4.0 & 3.5 & 2.5 & 2 & 1 & 1 & 2.5 & 3.0 & 2.5 & 1.5 & 16468.619 & 16468.614 & 0.005 & 1.600 \\
\hline 3 & 1 & 2 & 2.5 & 2.0 & 2.5 & 2.5 & 2 & 1 & 1 & 1.5 & 1.0 & 1.5 & 1.5 & 16468.773 & 16468.773 & 0.000 & 1.709 \\
\hline 3 & 1 & 2 & 2.5 & 3.0 & 3.5 & 4.5 & 2 & 1 & 1 & 1.5 & 2.0 & 2.5 & 3.5 & 16469.173 & 16469.173 & -0.000 & 3.768 \\
\hline 3 & 1 & 2 & 2.5 & 3.0 & 3.5 & 3.5 & 2 & 1 & 1 & 1.5 & 2.0 & 2.5 & 2.5 & 16469.273 & 16469.273 & -0.000 & 2.856 \\
\hline 3 & 1 & 2 & 2.5 & 3.0 & 2.5 & 3.5 & 2 & 1 & 1 & 2.5 & 3.0 & 2.5 & 2.5 & 16469.522 & 16469.520 & 0.002 & 2.323 \\
\hline 3 & 1 & 2 & 2.5 & 3.0 & 3.5 & 2.5 & 2 & 1 & 1 & 1.5 & 2.0 & 2.5 & 1.5 & 16469.975 & 16469.975 & 0.000 & 2.066 \\
\hline 3 & 1 & 2 & 3.5 & 3.0 & 2.5 & 2.5 & 2 & 1 & 1 & 2.5 & 2.0 & 1.5 & 1.5 & 16470.036 & 16470.035 & 0.001 & 1.727 \\
\hline 3 & 1 & 2 & 3.5 & 3.0 & 2.5 & 3.5 & 2 & 1 & 1 & 2.5 & 2.0 & 1.5 & 2.5 & 16470.892 & 16470.892 & -0.000 & 2.718 \\
\hline 3 & 1 & 2 & 3.5 & 4.0 & 4.5 & 3.5 & 2 & 1 & 1 & 2.5 & 3.0 & 3.5 & 2.5 & 16471.097 & 16471.099 & -0.002 & 2.976 \\
\hline 3 & 1 & 2 & 3.5 & 4.0 & 4.5 & 4.5 & 2 & 1 & 1 & 2.5 & 3.0 & 3.5 & 3.5 & 16471.186 & 16471.185 & 0.001 & 3.746 \\
\hline 3 & 1 & 2 & 3.5 & 4.0 & 3.5 & 4.5 & 2 & 1 & 1 & 2.5 & 3.0 & 2.5 & 3.5 & 16471.633 & 16471.636 & -0.003 & 3.762 \\
\hline 3 & 1 & 2 & 3.5 & 4.0 & 4.5 & 5.5 & 2 & 1 & 1 & 2.5 & 3.0 & 3.5 & 4.5 & 16471.658 & 16471.657 & 0.001 & 4.570 \\
\hline 4 & 1 & 4 & 3.5 & 3.0 & 2.5 & 2.5 & 3 & 1 & 3 & 2.5 & 2.0 & 1.5 & 1.5 & 20951.308 & 20951.307 & 0.001 & 1.718 \\
\hline 4 & 1 & 4 & 3.5 & 3.0 & 3.5 & 3.5 & 3 & 1 & 3 & 2.5 & 2.0 & 2.5 & 2.5 & 20951.588 & 20951.588 & 0.000 & 2.489 \\
\hline 4 & 1 & 4 & 3.5 & 4.0 & 3.5 & 3.5 & 3 & 1 & 3 & 2.5 & 3.0 & 2.5 & 2.5 & 20952.247 & 20952.248 & -0.001 & 2.925 \\
\hline 4 & 1 & 4 & 3.5 & 4.0 & 3.5 & 4.5 & 3 & 1 & 3 & 2.5 & 3.0 & 2.5 & 3.5 & 20952.843 & 20952.841 & 0.002 & 3.992 \\
\hline 4 & 1 & 4 & 3.5 & 3.0 & 3.5 & 4.5 & 3 & 1 & 3 & 2.5 & 2.0 & 2.5 & 3.5 & 20952.883 & 20952.883 & -0.000 & 3.534 \\
\hline 4 & 1 & 4 & 4.5 & 4.0 & 3.5 & 2.5 & 3 & 1 & 3 & 3.5 & 3.0 & 2.5 & 1.5 & 20953.203 & 20953.204 & -0.001 & 2.033 \\
\hline 4 & 1 & 4 & 3.5 & 3.0 & 2.5 & 3.5 & 3 & 1 & 3 & 2.5 & 2.0 & 1.5 & 2.5 & 20953.419 & 20953.418 & 0.001 & 2.549 \\
\hline 4 & 1 & 4 & 3.5 & 4.0 & 4.5 & 4.5 & 3 & 1 & 3 & 2.5 & 3.0 & 3.5 & 3.5 & 20953.552 & 20953.552 & -0.000 & 3.934 \\
\hline 4 & 1 & 4 & 3.5 & 4.0 & 4.5 & 3.5 & 3 & 1 & 3 & 3.5 & 3.0 & 2.5 & 2.5 & 20953.712 & 20953.713 & -0.001 & 3.080 \\
\hline 4 & 1 & 4 & 4.5 & 4.0 & 4.5 & 3.5 & 3 & 1 & 3 & 3.5 & 3.0 & 3.5 & 2.5 & 20953.820 & 20953.820 & -0.000 & 2.884 \\
\hline 4 & 1 & 4 & 4.5 & 4.0 & 4.5 & 4.5 & 3 & 1 & 3 & 3.5 & 3.0 & 3.5 & 3.5 & 20953.946 & 20953.947 & -0.001 & 3.683 \\
\hline 4 & 1 & 4 & 3.5 & 4.0 & 4.5 & 5.5 & 3 & 1 & 3 & 2.5 & 3.0 & 3.5 & 4.5 & 20954.101 & 20954.100 & 0.001 & 4.996 \\
\hline 4 & 1 & 4 & 4.5 & 4.0 & 4.5 & 5.5 & 3 & 1 & 3 & 3.5 & 3.0 & 3.5 & 4.5 & 20954.154 & 20954.154 & -0.000 & 4.633 \\
\hline 4 & 1 & 4 & 4.5 & 5.0 & 4.5 & 3.5 & 3 & 1 & 3 & 3.5 & 4.0 & 3.5 & 2.5 & 20954.830 & 20954.830 & -0.000 & 2.631 \\
\hline 4 & 1 & 4 & 4.5 & 4.0 & 3.5 & 4.5 & 3 & 1 & 3 & 3.5 & 3.0 & 2.5 & 3.5 & 20954.944 & 20954.943 & 0.001 & 4.028 \\
\hline 4 & 1 & 4 & 4.5 & 5.0 & 5.5 & 4.5 & 3 & 1 & 3 & 3.5 & 4.0 & 4.5 & 3.5 & 20954.990 & 20954.991 & -0.001 & 3.975 \\
\hline 4 & 1 & 4 & 4.5 & 5.0 & 4.5 & 4.5 & 3 & 1 & 3 & 3.5 & 4.0 & 3.5 & 3.5 & 20955.306 & 20955.307 & -0.001 & 3.952 \\
\hline 4 & 1 & 4 & 4.5 & 5.0 & 5.5 & 5.5 & 3 & 1 & 3 & 3.5 & 4.0 & 4.5 & 4.5 & 20955.421 & 20955.421 & -0.000 & 4.773 \\
\hline 4 & 1 & 4 & 4.5 & 5.0 & 4.5 & 5.5 & 3 & 1 & 3 & 3.5 & 4.0 & 3.5 & 4.5 & 20955.736 & 20955.736 & 0.000 & 4.991 \\
\hline 4 & 1 & 4 & 4.5 & 5.0 & 5.5 & 6.5 & 3 & 1 & 3 & 3.5 & 4.0 & 4.5 & 5.5 & 20955.881 & 20955.881 & -0.000 & 5.832 \\
\hline 4 & 0 & 4 & 4.5 & 4.0 & 3.5 & 3.5 & 3 & 0 & 3 & 3.5 & 3.0 & 2.5 & 3.5 & 21439.331 & 21439.332 & -0.001 & 0.386 \\
\hline 4 & 0 & 4 & 4.5 & 5.0 & 5.5 & 4.5 & 3 & 0 & 3 & 3.5 & 4.0 & 4.5 & 3.5 & 21439.986 & 21439.987 & -0.001 & 4.337 \\
\hline 4 & 0 & 4 & 4.5 & 5.0 & 4.5 & 3.5 & 3 & 0 & 3 & 3.5 & 4.0 & 3.5 & 2.5 & 21440.034 & 21440.034 & -0.000 & 3.244 \\
\hline 4 & 0 & 4 & 4.5 & 5.0 & 5.5 & 5.5 & 3 & 0 & 3 & 3.5 & 4.0 & 4.5 & 4.5 & 21440.168 & 21440.167 & 0.001 & 5.240 \\
\hline 4 & 0 & 4 & 4.5 & 5.0 & 4.5 & 5.5 & 3 & 0 & 3 & 3.5 & 4.0 & 3.5 & 4.5 & 21440.194 & 21440.191 & 0.003 & 5.318 \\
\hline 4 & 0 & 4 & 4.5 & 5.0 & 5.5 & 6.5 & 3 & 0 & 3 & 3.5 & 4.0 & 4.5 & 5.5 & 21440.231 & 21440.231 & 0.000 & 6.222 \\
\hline 4 & 0 & 4 & 4.5 & 5.0 & 4.5 & 4.5 & 3 & 0 & 3 & 3.5 & 4.0 & 3.5 & 3.5 & 21440.317 & 21440.319 & -0.002 & 4.239 \\
\hline 4 & 0 & 4 & 4.5 & 4.0 & 4.5 & 3.5 & 3 & 0 & 3 & 3.5 & 3.0 & 3.5 & 2.5 & 21440.635 & 21440.638 & -0.003 & 3.189 \\
\hline 4 & 0 & 4 & 4.5 & 4.0 & 4.5 & 4.5 & 3 & 0 & 3 & 3.5 & 3.0 & 3.5 & 3.5 & 21440.908 & 21440.906 & 0.002 & 3.958 \\
\hline 4 & 0 & 4 & 3.5 & 3.0 & 2.5 & 2.5 & 3 & 0 & 3 & 2.5 & 2.0 & 1.5 & 1.5 & 21441.044 & 21441.052 & -0.008 & 1.795 \\
\hline 4 & 0 & 4 & 4.5 & 4.0 & 3.5 & 4.5 & 3 & 0 & 3 & 3.5 & 3.0 & 2.5 & 3.5 & 21441.126 & 21441.124 & 0.002 & 4.070 \\
\hline 4 & 0 & 4 & 4.5 & 4.0 & 4.5 & 5.5 & 3 & 0 & 3 & 3.5 & 3.0 & 3.5 & 4.5 & 21441.178 & 21441.176 & 0.002 & 4.786 \\
\hline 4 & 0 & 4 & 4.5 & 4.0 & 3.5 & 3.5 & 3 & 0 & 3 & 3.5 & 3.0 & 2.5 & 2.5 & 21441.242 & 21441.246 & -0.004 & 3.140 \\
\hline 4 & 0 & 4 & 3.5 & 4.0 & 3.5 & 4.5 & 3 & 0 & 3 & 2.5 & 3.0 & 2.5 & 3.5 & 21441.323 & 21441.321 & 0.002 & 3.641 \\
\hline 4 & 0 & 4 & 3.5 & 4.0 & 3.5 & 3.5 & 3 & 0 & 3 & 2.5 & 3.0 & 2.5 & 2.5 & 21441.455 & 21441.453 & 0.002 & 2.954 \\
\hline 4 & 0 & 4 & 4.5 & 4.0 & 3.5 & 2.5 & 3 & 0 & 3 & 3.5 & 3.0 & 2.5 & 1.5 & 21441.484 & 21441.483 & 0.001 & 2.277 \\
\hline 4 & 0 & 4 & 3.5 & 4.0 & 4.5 & 5.5 & 3 & 0 & 3 & 2.5 & 3.0 & 3.5 & 4.5 & 21441.670 & 21441.671 & -0.001 & 5.331 \\
\hline 4 & 0 & 4 & 3.5 & 4.0 & 4.5 & 4.5 & 3 & 0 & 3 & 2.5 & 3.0 & 3.5 & 3.5 & 21441.684 & 21441.683 & 0.001 & 4.254 \\
\hline 4 & 0 & 4 & 3.5 & 3.0 & 3.5 & 3.5 & 3 & 0 & 3 & 2.5 & 2.0 & 2.5 & 2.5 & 21441.811 & 21441.811 & 0.000 & 3.075 \\
\hline 4 & 0 & 4 & 3.5 & 4.0 & 4.5 & 3.5 & 3 & 0 & 3 & 2.5 & 3.0 & 3.5 & 2.5 & 21442.054 & 21442.058 & -0.004 & 3.332 \\
\hline 4 & 0 & 4 & 3.5 & 3.0 & 3.5 & 2.5 & 3 & 0 & 3 & 2.5 & 2.0 & 2.5 & 1.5 & 21442.089 & 21442.085 & 0.004 & 2.261 \\
\hline 4 & 0 & 4 & 3.5 & 3.0 & 3.5 & 4.5 & 3 & 0 & 3 & 2.5 & 2.0 & 2.5 & 3.5 & 21442.130 & 21442.130 & -0.000 & 4.147 \\
\hline 4 & 0 & 4 & 3.5 & 4.0 & 3.5 & 4.5 & 3 & 0 & 3 & 3.5 & 3.0 & 3.5 & 4.5 & 21442.755 & 21442.755 & 0.000 & 0.649 \\
\hline 4 & 1 & 3 & 4.5 & 4.0 & 4.5 & 5.5 & 3 & 1 & 2 & 3.5 & 3.0 & 3.5 & 4.5 & 21956.727 & 21956.726 & 0.001 & 4.510 \\
\hline 4 & 1 & 3 & 4.5 & 4.0 & 3.5 & 3.5 & 3 & 1 & 2 & 3.5 & 4.0 & 3.5 & 2.5 & 21957.077 & 21957.076 & 0.001 & 2.859 \\
\hline 4 & 1 & 3 & 4.5 & 4.0 & 4.5 & 4.5 & 3 & 1 & 2 & 3.5 & 3.0 & 3.5 & 3.5 & 21957.112 & 21957.110 & 0.002 & 3.673 \\
\hline 4 & 1 & 3 & 4.5 & 4.0 & 4.5 & 3.5 & 3 & 1 & 2 & 3.5 & 3.0 & 3.5 & 2.5 & 21957.368 & 21957.369 & -0.001 & 2.989 \\
\hline 4 & 1 & 3 & 4.5 & 5.0 & 4.5 & 4.5 & 3 & 1 & 2 & 3.5 & 4.0 & 3.5 & 3.5 & 21957.455 & 21957.455 & 0.000 & 3.600 \\
\hline 4 & 1 & 3 & 3.5 & 3.0 & 3.5 & 4.5 & 3 & 1 & 2 & 2.5 & 2.0 & 2.5 & 3.5 & 21957.508 & 21957.509 & -0.001 & 3.909 \\
\hline 4 & 1 & 3 & 4.5 & 5.0 & 5.5 & 4.5 & 3 & 1 & 2 & 3.5 & 4.0 & 4.5 & 3.5 & 21957.957 & 21957.959 & -0.002 & 4.117 \\
\hline 4 & 1 & 3 & 4.5 & 5.0 & 5.5 & 5.5 & 3 & 1 & 2 & 3.5 & 4.0 & 4.5 & 4.5 & 21957.999 & 21957.997 & 0.002 & 4.955 \\
\hline 4 & 1 & 3 & 4.5 & 5.0 & 5.5 & 6.5 & 3 & 1 & 2 & 3.5 & 4.0 & 4.5 & 5.5 & 21958.183 & 21958.185 & -0.002 & 5.833 \\
\hline 4 & 1 & 3 & 4.5 & 5.0 & 4.5 & 5.5 & 3 & 1 & 2 & 3.5 & 4.0 & 3.5 & 4.5 & 21958.210 & 21958.204 & 0.006 & 4.969 \\
\hline
\end{tabular}


Table A.1. continued.

\begin{tabular}{|c|c|c|c|c|c|c|c|c|c|c|c|c|c|c|c|c|c|}
\hline$N^{\prime}$ & $K_{a}^{\prime}$ & $K_{c}^{\prime}$ & $J^{\prime}$ & $F_{1}^{\prime}$ & $F_{2}^{\prime}$ & $F^{\prime}$ & $N^{\prime \prime}$ & $K_{a}^{\prime \prime}$ & $K_{c}^{\prime \prime}$ & $J^{\prime \prime}$ & $F_{1}^{\prime \prime}$ & $F_{2}^{\prime \prime}$ & $F^{\prime \prime}$ & $\begin{array}{c}v_{o b s} \\
(\mathrm{MHz})\end{array}$ & $\begin{array}{c}v_{\text {calc }} \\
(\mathrm{MHz})\end{array}$ & $\begin{array}{c}\text { Obs-Calc } \\
\text { (MHz) }\end{array}$ & Int. $^{a}$ \\
\hline 4 & 1 & 3 & 3.5 & 4.0 & 4.5 & 5.5 & 3 & 1 & 2 & 2.5 & 3.0 & 3.5 & 4.5 & 21958.333 & 21958.334 & -0.001 & 4.978 \\
\hline 4 & 1 & 3 & 3.5 & 4.0 & 3.5 & 2.5 & 3 & 1 & 2 & 2.5 & 3.0 & 2.5 & 1.5 & 21958.482 & 21958.491 & -0.009 & 2.135 \\
\hline 4 & 1 & 3 & 3.5 & 4.0 & 4.5 & 3.5 & 3 & 1 & 2 & 2.5 & 3.0 & 3.5 & 2.5 & 21958.638 & 21958.637 & 0.001 & 3.153 \\
\hline 4 & 1 & 3 & 3.5 & 4.0 & 3.5 & 4.5 & 3 & 1 & 2 & 3.5 & 3.0 & 2.5 & 3.5 & 21958.685 & 21958.683 & 0.002 & 3.926 \\
\hline 4 & 1 & 3 & 3.5 & 3.0 & 3.5 & 2.5 & 3 & 1 & 2 & 2.5 & 2.0 & 2.5 & 1.5 & 21958.782 & 21958.782 & 0.000 & 2.118 \\
\hline 1 & 1 & 0 & 1.5 & 2.0 & 1.5 & 2.5 & 1 & 0 & 1 & 1.5 & 2.0 & 1.5 & 2.5 & 26595.729 & 26595.728 & 0.001 & 1.559 \\
\hline 1 & 1 & 0 & 1.5 & 2.0 & 2.5 & 3.5 & 1 & 0 & 1 & 1.5 & 2.0 & 2.5 & 3.5 & 26597.165 & 26597.163 & 0.002 & 2.577 \\
\hline 1 & 1 & 0 & 1.5 & 1.0 & 1.5 & 2.5 & 1 & 0 & 1 & 0.5 & 1.0 & 1.5 & 1.5 & 26599.936 & 26599.939 & -0.003 & 0.771 \\
\hline 1 & 1 & 0 & 1.5 & 2.0 & 2.5 & 2.5 & 1 & 0 & 1 & 1.5 & 2.0 & 2.5 & 2.5 & 26601.798 & 26601.798 & 0.000 & 1.824 \\
\hline 1 & 1 & 0 & 1.5 & 1.0 & 1.5 & 2.5 & 1 & 0 & 1 & 1.5 & 2.0 & 1.5 & 2.5 & 26603.007 & 26603.005 & 0.002 & 0.501 \\
\hline 1 & 1 & 0 & 1.5 & 2.0 & 2.5 & 3.5 & 1 & 0 & 1 & 0.5 & 1.0 & 1.5 & 2.5 & 26603.908 & 26603.905 & 0.003 & 1.362 \\
\hline 1 & 1 & 0 & 1.5 & 1.0 & 1.5 & 1.5 & 1 & 0 & 1 & 1.5 & 2.0 & 1.5 & 1.5 & 26604.708 & 26604.708 & -0.000 & 0.751 \\
\hline 1 & 1 & 0 & 1.5 & 1.0 & 1.5 & 2.5 & 1 & 0 & 1 & 1.5 & 2.0 & 2.5 & 3.5 & 26621.964 & 26621.962 & 0.002 & 0.753 \\
\hline 1 & 1 & 0 & 0.5 & 1.0 & 1.5 & 1.5 & 1 & 0 & 1 & 1.5 & 1.0 & 1.5 & 1.5 & 26630.457 & 26630.458 & -0.001 & 1.070 \\
\hline 5 & 0 & 5 & 5.5 & 6.0 & 5.5 & 4.5 & 4 & 0 & 4 & 4.5 & 5.0 & 4.5 & 3.5 & 26786.229 & 26786.228 & 0.001 & 1.454 \\
\hline 5 & 0 & 5 & 5.5 & 6.0 & 6.5 & 5.5 & 4 & 0 & 4 & 4.5 & 5.0 & 5.5 & 4.5 & 26786.687 & 26786.688 & -0.001 & 5.354 \\
\hline 5 & 0 & 5 & 5.5 & 6.0 & 6.5 & 6.5 & 4 & 0 & 4 & 4.5 & 5.0 & 5.5 & 5.5 & 26786.852 & 26786.851 & 0.001 & 6.272 \\
\hline 5 & 0 & 5 & 5.5 & 6.0 & 5.5 & 6.5 & 4 & 0 & 4 & 4.5 & 5.0 & 4.5 & 5.5 & 26786.882 & 26786.882 & 0.000 & 6.352 \\
\hline 5 & 0 & 5 & 5.5 & 6.0 & 6.5 & 7.5 & 4 & 0 & 4 & 4.5 & 5.0 & 5.5 & 6.5 & 26786.912 & 26786.912 & 0.000 & 7.272 \\
\hline 5 & 0 & 5 & 5.5 & 6.0 & 5.5 & 5.5 & 4 & 0 & 4 & 4.5 & 5.0 & 4.5 & 4.5 & 26786.945 & 26786.944 & 0.001 & 5.278 \\
\hline 5 & 0 & 5 & 5.5 & 5.0 & 5.5 & 4.5 & 4 & 0 & 4 & 4.5 & 4.0 & 4.5 & 3.5 & 26787.304 & 26787.305 & -0.001 & 4.227 \\
\hline 5 & 0 & 5 & 5.5 & 5.0 & 5.5 & 5.5 & 4 & 0 & 4 & 4.5 & 4.0 & 4.5 & 4.5 & 26787.545 & 26787.545 & -0.000 & 5.049 \\
\hline 5 & 0 & 5 & 5.5 & 5.0 & 5.5 & 6.5 & 4 & 0 & 4 & 4.5 & 4.0 & 4.5 & 5.5 & 26787.785 & 26787.784 & 0.001 & 5.947 \\
\hline 5 & 0 & 5 & 5.5 & 5.0 & 4.5 & 5.5 & 4 & 0 & 4 & 4.5 & 4.0 & 3.5 & 4.5 & 26787.828 & 26787.828 & 0.000 & 5.212 \\
\hline 5 & 0 & 5 & 5.5 & 5.0 & 4.5 & 4.5 & 4 & 0 & 4 & 4.5 & 4.0 & 3.5 & 3.5 & 26787.988 & 26787.989 & -0.001 & 4.212 \\
\hline 5 & 0 & 5 & 4.5 & 5.0 & 4.5 & 5.5 & 4 & 0 & 4 & 3.5 & 4.0 & 3.5 & 4.5 & 26788.171 & 26788.169 & 0.002 & 4.844 \\
\hline 5 & 0 & 5 & 4.5 & 5.0 & 4.5 & 3.5 & 4 & 0 & 4 & 4.5 & 4.0 & 3.5 & 2.5 & 26788.237 & 26788.237 & -0.000 & 3.322 \\
\hline 5 & 0 & 5 & 4.5 & 5.0 & 5.5 & 6.5 & 4 & 0 & 4 & 3.5 & 4.0 & 4.5 & 5.5 & 26788.433 & 26788.434 & -0.001 & 6.360 \\
\hline 5 & 0 & 5 & 4.5 & 4.0 & 3.5 & 3.5 & 4 & 0 & 4 & 3.5 & 3.0 & 2.5 & 2.5 & 26788.458 & 26788.456 & 0.002 & 2.943 \\
\hline 5 & 0 & 5 & 4.5 & 5.0 & 5.5 & 5.5 & 4 & 0 & 4 & 3.5 & 4.0 & 4.5 & 4.5 & 26788.532 & 26788.532 & -0.000 & 5.295 \\
\hline 5 & 0 & 5 & 4.5 & 5.0 & 5.5 & 4.5 & 4 & 0 & 4 & 3.5 & 4.0 & 4.5 & 3.5 & 26788.840 & 26788.844 & -0.004 & 4.361 \\
\hline 5 & 0 & 5 & 4.5 & 4.0 & 4.5 & 4.5 & 4 & 0 & 4 & 3.5 & 3.0 & 3.5 & 3.5 & 26788.865 & 26788.864 & 0.001 & 4.167 \\
\hline 5 & 0 & 5 & 4.5 & 4.0 & 4.5 & 5.5 & 4 & 0 & 4 & 3.5 & 3.0 & 3.5 & 4.5 & 26788.986 & 26788.985 & 0.001 & 5.237 \\
\hline 5 & 0 & 5 & 4.5 & 4.0 & 4.5 & 3.5 & 4 & 0 & 4 & 3.5 & 3.0 & 3.5 & 2.5 & 26789.084 & 26789.083 & 0.001 & 3.311 \\
\hline 2 & 1 & 1 & 2.5 & 3.0 & 2.5 & 3.5 & 2 & 0 & 2 & 2.5 & 3.0 & 2.5 & 3.5 & 26855.660 & & -0.003 & 3.416 \\
\hline 2 & 1 & 1 & 2.5 & 3.0 & 3.5 & 4.5 & 2 & 0 & 2 & 2.5 & 3.0 & 3.5 & 4.5 & 26855.700 & 26855.700 & 0.000 & 4.105 \\
\hline 2 & 1 & 1 & 2.5 & 3.0 & 2.5 & 2.5 & 2 & 0 & 2 & 2.5 & 3.0 & 2.5 & 2.5 & 26858.924 & 26858.924 & -0.000 & 2.020 \\
\hline 2 & 1 & 1 & 2.5 & 3.0 & 3.5 & 3.5 & 2 & 0 & 2 & 2.5 & 3.0 & 3.5 & 3.5 & 26859.314 & 26859.315 & -0.001 & 3.308 \\
\hline 2 & 1 & 1 & 2.5 & 3.0 & 3.5 & 4.5 & 2 & 0 & 2 & 2.5 & 2.0 & 2.5 & 3.5 & 26861.251 & 26861.252 & -0.001 & 0.867 \\
\hline 2 & 1 & 1 & 2.5 & 2.0 & 1.5 & 2.5 & 2 & 0 & 2 & 2.5 & 2.0 & 1.5 & 2.5 & 26867.205 & 26867.206 & -0.001 & 1.473 \\
\hline 2 & 1 & 1 & 2.5 & 2.0 & 2.5 & 2.5 & 2 & 0 & 2 & 2.5 & 2.0 & 2.5 & 2.5 & 26868.565 & 26868.566 & -0.001 & 1.441 \\
\hline 2 & 1 & 1 & 2.5 & 2.0 & 2.5 & 3.5 & 2 & 0 & 2 & 2.5 & 2.0 & 2.5 & 3.5 & 26870.950 & 26870.950 & -0.000 & 1.781 \\
\hline 2 & 1 & 1 & 1.5 & 2.0 & 2.5 & 1.5 & 2 & 0 & 2 & 1.5 & 2.0 & 2.5 & 1.5 & 26874.004 & 26874.003 & 0.001 & 1.553 \\
\hline 2 & 1 & 1 & 1.5 & 2.0 & 2.5 & 2.5 & 2 & 0 & 2 & 1.5 & 2.0 & 2.5 & 2.5 & 26876.528 & 26876.526 & 0.002 & 2.116 \\
\hline 2 & 1 & 1 & 1.5 & 2.0 & 2.5 & 3.5 & 2 & 0 & 2 & 1.5 & 2.0 & 2.5 & 3.5 & 26877.421 & 26877.421 & -0.000 & 3.227 \\
\hline 2 & 1 & 1 & 1.5 & 1.0 & 1.5 & 2.5 & 2 & 0 & 2 & 1.5 & 1.0 & 1.5 & 2.5 & 26891.143 & 26891.143 & 0.000 & 1.829 \\
\hline
\end{tabular}

Notes. ${ }^{a}$ Calculated line strength factor. 